\title{
Policy Regimes, Policy Shifts, and U.S. Business Cycles
}

\author{
Saroj Bhattarai \\ Penn State
}

\author{
Jae Won Lee \\ Rutgers University
}

\author{
Woong Yong Park* \\ University of Hong Kong
}

\begin{abstract}
Using an estimated DSGE model that features monetary and fiscal policy interactions and allows for equilibrium indeterminacy, we find that a passive monetary and passive fiscal policy regime prevailed in the pre-Volcker period while an active monetary and passive fiscal policy regime prevailed post-Volcker. Since both monetary and fiscal policies were passive pre-Volcker, there was equilibrium indeterminacy that gave rise to self-fulfilling beliefs and resulted in substantially different transmission mechanisms of policy as compared to conventional models: unanticipated increases in interest rates increased inflation and output while unanticipated increases in lump-sum taxes decreased inflation and output. Unanticipated shifts in monetary and fiscal policies however, played no substantial role in explaining the variation of inflation and output at any horizon in either of the time periods. Pre-Volcker, in sharp contrast to post-Volcker, we find that a time-varying inflation target does not explain low-frequency movements in inflation. A combination of shocks account for the dynamics of output, inflation, and government debt, with the relative importance of a particular shock quite different in the two timeperiods due to changes in the systematic responses of policy. Finally, in a counterfactual exercise, we show that had the monetary policy regime of the post-Volcker era been in place pre-Volcker, inflation volatility would have been lower by $34 \%$ and the rise of inflation in the $1970 \mathrm{~s}$ would not have occurred.
\end{abstract}

JEL Classification: C52, C54, E31, E32, E52, E63

Keywords: Monetary and fiscal policy regimes; Monetary and fiscal policy transmission; Indeterminacy; Self-fulfilling beliefs; Output, inflation, and debt dynamics; Bayesian estimation of DSGE models

${ }^{*}$ Bhattarai: 615 Kern Building, University Park, PA 16802, sub31@psu.edu. Lee: 75 Hamilton Street, NJ Hall, New Brunswick, NJ 08901, jwlee@econ.rutgers.edu. Park: School of Economics and Finance, Pokfulam Road, Hong Kong SAR, wypark@hku.hk. We are grateful to Eric Leeper, Chris Sims, seminar participants at the Federal Reserve Bank of Kansas City and Bank of Korea, and conference participants at the Annual American Economic Association Meetings for comments and criticisms. This version: Jan 2012. 


\section{Introduction}

Macroeconomic models that are estimated and used for monetary policy analysis typically abstract from non-trivial monetary and fiscal policy interactions. A theoretical literature starting with the work of Sargent and Wallace (1981) and Aiyagari and Gertler (1985) has however, long emphasized that monetary and fiscal policies jointly determine equilibrium model dynamics. Moreover, the recent crisis which has brought to the fore issues of monetary and fiscal policy interactions, due to unconventional monetary policy actions that can have significant effects on the government budget and great uncertainty about the future course of fiscal policy, provides an additional impetus to model monetary and fiscal policies jointly in macroeconomic models geared towards policy analysis.

Motivated by these considerations, we extend a standard DSGE model that features nominal and real rigidities to include an explicitly specified description of fiscal policy. Similar to the standard feedback rule for monetary policy that governs how nominal interest rates respond to inflation and output, our model features a feedback rule for fiscal policy that determines how taxes respond to debt, output, and government spending. ${ }^{1}$ Moreover, the equilibrium of the economy in our model has to be consistent with the intertemporal government budget constraint.

In such a set-up, as shown by Leeper (1991), Sims (1994), and Woodford (1995), the equilibrium model dynamics depend crucially on monetary and fiscal policy stances, that is, the strength with which policies respond to the state of the economy. Equilibrium in our model is determinate under two cases: either when both the interest rate response to inflation and the tax response to debt are strong (an active monetary and passive fiscal policy regime) or when both the responses are weak (a passive monetary and active fiscal policy regime). Indeterminacy of equilibrium arises when a weak interest rate response to inflation is coupled with a strong response of taxes to debt (a passive monetary and passive fiscal policy regime). ${ }^{2}$

We use this model as a laboratory to answer four broad set of questions. First, what monetary and fiscal policy regimes characterized post-War U.S. data? Second, what were the monetary and fiscal policy transmission mechanisms over time? Third, which shocks were the primary sources of short and long-run variation in output, inflation, and government debt? Fourth, what would have been the path of inflation, especially with regards to the rise of inflation in the 1970 s, under a (counterfactual) monetary policy regime different from the estimated one?

\footnotetext{
${ }^{1}$ We consider lump-sum taxes and transfers, one-period riskless nominal debt, and exogenous government spending for simplicity in the basic model.

${ }^{2}$ We use the language of Leeper (1991) in characterizing policies as active or passive. The exact bounds for active and passive policies are model-specific and we make these definitions precise later in the paper after introducing the model.
} 
We conduct our empirical analysis, following the literature, by splitting the data into two time-periods based on the timing of Paul Volcker's chairmanship at the Federal Reserve: a pre-Volcker period and a post-Volcker period. ${ }^{3}$ Using likelihood based methods, we fit our model to data on nominal, real, and fiscal variables. In particular, we use the likelihood based estimation method proposed by Lubik and Schorfheide (2004) that allows for indeterminacy in a DSGE model. ${ }^{4}$ Allowing for the possibility of indeterminacy in an estimated DSGE model that features monetary and fiscal policy interactions is a distinct contribution of our paper, and one that matters significantly for our results. ${ }^{5}$ Using a Bayesian model comparison exercise, we first assess the best-fitting policy regime in the two time-periods. With the posterior distribution of the parameters of the best-fitting model at hand, we then conduct several impulse response, variance decomposition, and counterfactual analyses.

Our main results are as follows. ${ }^{6}$ First, using Bayesian model comparison we find that preVolcker, the best-fitting model is a passive monetary and passive fiscal policy regime while post-Volcker, it is an active monetary and passive fiscal policy regime. Thus, our results are consistent with those of Clarida, Gali, and Gertler (2000), who using univariate methods, provide evidence for a weak response of interest rates to expected inflation in the pre-Volcker period. In a DSGE context, our results are also consistent with those in Lubik and Schorfheide (2004). As we discuss below however, our results on the transmission mechanisms of monetary and fiscal policies in the pre-Volcker period are in sharp contrast to the literature.

Second, using impulse response analysis we show that the transmission mechanisms of monetary and fiscal policies were substantially different in the two time periods. In particular, since both monetary and fiscal policies were passive pre-Volcker, there was equilibrium indeterminacy that substantially altered the propagation mechanism of fundamental shocks in the economy due to self-fulfilling beliefs of the agents. For example, while pre-Volcker, an unanticipated increase in interest rates led to an increase in output and inflation, post-Volcker, it led to a decline in output and inflation. Moreover, while pre-Volcker, an unanticipated increase in the (lump-sum) tax revenues-to-output ratio led to a decline in output and inflation, post-Volcker, it had no effects on output or inflation.

Pre-Volcker, the response of the economy to unanticipated policy shifts was thus similar

\footnotetext{
${ }^{3}$ Following the literature, we define the pre-Volcker sample from 1960:Q1 to 1979:Q2 and a post-Volcker sample from 1982:Q4 onwards.

${ }^{4}$ Briefly, this method which we discuss in detail later, indexes the multiples solutions under indeterminacy using additional parameters and then using a Bayesian inference procedure constructs, conditional on the observed data, probability weights for the determinacy and indeterminacy regions of the parameter space.

${ }^{5}$ Lubik and Schorfheide (2004) assess the role of equilibrium indeterminacy due to passive monetary policy but abstract from fiscal policy while Traum and Yang (2011) tackle monetary and fiscal policy interactions but abstract from the possibility of equilibrium indeterminacy. Bianchi and Ilut (2012) estimate a model with a one-time unanticipated change from an active fiscal to passive fiscal regime and use it to explain the rise of inflation in the $1970 \mathrm{~s}$, while also abstracting from equilibrium indeterminacy.

${ }^{6}$ Some preliminary and partial results of this research appear in Bhattarai, Lee, and Park (2012).
} 
to that predicted by the fiscal theory of the price level (FTPL). ${ }^{7}$ Under FTPL, an increase in interest payments due to a contractionary monetary policy increases spending by agents because of a positive wealth effect. This then leads to an increase in inflation and output. Moreover, shifts in fiscal policy influence inflation and output under FTPL due to wealth effects. In contrast, post-Volcker, the response of the economy followed the predictions of standard models of price determination.

Our findings in an estimated DSGE model that pre-Volcker, inflation increased both on impact and afterwards following a monetary contraction and unanticipated movements in lump-sum taxes affected both inflation and output is new to the literature. For example, Lubik and Schorfheide (2004), who only model monetary policy, find that in their indeterminate model in the pre-Volcker period, inflation does not rise on impact following an interest rate increase. Our results are in fact quite close to those obtained from the identified VAR literature. Since the work of Sims (1992), it has been observed that in many VAR specifications, inflation tends to increase on impact following a contractionary monetary policy shock. This has been dubbed the "price puzzle" in the literature since it goes against the predictions of the standard models of price determination. Hanson (2004) in a comprehensive study showed that this "price puzzle" seems to be a feature only of the pre-Volcker period and not for the entire post-War U.S. data. Our results are thus consistent with his findings and moreover, provide a model based interpretation. In addition, Sims (2011) provides some VAR based evidence on predictory power of fiscal variables in explaining U.S. inflation. We provide complementary evidence from our estimated model on this front, albeit only for the pre-Volcker period.

Third, using variance decomposition analysis we find that in both the time-periods and at both the short and long-run, unanticipated shifts in monetary and fiscal policies play only a minor role in explaining the dynamics of inflation and output. ${ }^{8}$ For example, for inflation, pre-Volcker, monetary and fiscal policy shocks explain less than $10 \%$ of the variation at both horizons. Post-Volcker, both the shocks explain basically no variation at either horizons. For output growth, pre-Volcker, monetary policy shocks explain around $1.6 \%$ and fiscal policy shocks explain around $6.0 \%$ of the variation in both the short and long-run. Post-Volcker, the monetary shock explains around $2.5 \%$ of the variation at both horizons while fiscal policy shocks explain basically no variation in output growth.

Our result that random variations in monetary policy do not explain much of the fluctuations in the data is consistent with the results in the identified VAR literature, for example,

\footnotetext{
${ }^{7}$ Canzoneri, Cumby, and Diba (2011) is a recent survey of the FTPL literature. In our model, FTPL is operative under a passive monetary and active fiscal policy regime. We find that our estimated best-fitting model pre-Volcker, a passive monetary and passive fiscal policy regime, mimics a passive monetary and active fiscal policy regime in important dimensions, even though it is not technically one where the FTPL has to be operative for sure.

${ }^{8}$ We focus on a 4 and 40 quarter horizon in our variance decomposition results.
} 
Sims and Zha (2006a). That the same conclusion also holds for random variations in fiscal policy, given by unanticipated movements in taxes, is completely new to the literature. While we find that random disturbances to policy do not matter, this does not imply at all that the systematic component to policy is also irrelevant. In fact, to the contrary, as we discuss below next, the propagation mechanisms of many shocks are substantially different in the two time-periods. This is exactly because the systematic responses of policy were dramatically different pre and post-Volcker, with different monetary and fiscal policy regimes operative in the two time-periods.

We also want to emphasize a similar point for indeterminacy. For the pre-Volcker period, sunspot shocks introduced due to indeterminacy play a minor role in explaining the dynamics of inflation and output: they are irrelevant for inflation dynamics and explain only around $11 \%$ of the variation at both horizons for output growth. While we thus find that sunspot shocks do not matter quantitatively, this does not necessarily imply that indeterminacy is not significant for explaining macroeconomic dynamics in the pre-Volcker period. In fact, indeterminacy due to passive monetary and fiscal policy leads to fundamentally different propagation mechanism of fundamental shocks, as agents' self-fulfilling beliefs play a key role in model dynamics.

Fourth, pre-Volcker, in sharp contrast to post-Volcker, we find that variations in the inflation target do not explain low-frequency movements in inflation. In the recent DSGE literature, a consensus finding has emerged that the long-run variation in inflation is explained mostly by shocks to the inflation target in the monetary reaction function. For example, Cogley, Primiceri, and Sargent (2010) show that both pre- and post-Volcker, smoothed inflation target shock tracks actual inflation remarkably well. While we find a similar result in the post-Volcker period, our results are quite different in the pre-Volcker era: inflation target shock explains virtually none of the long-run variation in inflation. The major reason for this difference is that we explicitly allow for the possibility of indeterminacy while estimating our model that features both monetary and fiscal policies. When the operative regime is active monetary and passive fiscal policy, as is the implicit assumption in Cogley, Primiceri, and Sargent (2010) for both the time-periods, then changes in the inflation target do explain inflation in the long-run since monetary policy fully controls inflation dynamics. Our best-fitting estimated model in the pre-Volcker features indeterminacy due to passive monetary policy, however. In this case, consider a decrease in the inflation target. This, through the central bank reaction function, does tend to increase the interest rate. An increase in the interest rate in this model though, as we pointed out above, tends to increase inflation. Thus, inflation target movements do not track actual inflation in the long-run.

Fifth, we find that the primary sources of short and long-run variation in inflation, output, and government debt are different in the two time periods as the propagation mechanisms of 
various shocks varies because of changes in policy stances. As mentioned above, post-Volcker, low frequency movement in inflation is explained by changes in the inflation target. The high frequency movement is mostly explained by mark-up shocks, which is also a standard result in the literature. In the pre-Volcker period, in contrast, the role of mark-up shocks gets reduced in the short-run while that of technology and demand shocks increases. Moreover, demand and technology shocks also explain much of the variation in the long-run along with a nontrivial role for mark-up shocks. In particular, since monetary policy regime was passive in the pre-Volcker period, demand shocks that would typically be stabilized under active monetary policy end up influencing inflation dynamics significantly.

For output growth, in both periods, a combination of shocks explain variation at the two horizons, but the importance of a particular shock is quite different. For example, while preVolcker markup shocks are the most important source of variation in output growth (around $33 \%$ ) at both horizons, post-Volcker, they account for no variation at either horizon. Thus, in the post-Volcker period, markup shocks, which lead to a trade-off between inflation and output stabilization under active monetary policy, affected inflation pre-dominantly without affecting output. Government spending, technology, and demand shocks are important in both the time periods, although the role of demand shocks is much higher in the post-Volcker period.

For the crucial fiscal variable, debt-to-output ratio, in both the time-periods, the shortrun variation is explained mostly by the transfer shock. In the long-run, a combination of shocks are important, but the relative contribution of these shocks across the two periods are again quite different. The policy regimes in place matter critically for the results as they lead to a different role for shocks in explaining inflation movements. For example, demand, technology, and mark-up shocks are important drivers of long-run variation in debt-to-output in the pre-Volcker period while shocks to the inflation target play a non-trivial role in the postVolcker period. This difference arises because as mentioned above, these shocks are important drivers of long-run inflation dynamics in the respective time periods, which plays a role in debt stabilization.

Our goal of addressing the sources of variation in macroeconomic variables at different horizons in a framework that allows for multiple shocks is similar to that of several VAR studies, such as Shapiro and Watson (1988), and several DSGE-based studies, such as Smets and Wouters (2007). One of our main contributions to this literature is to analyze these issues by fitting a DSGE model to data on both conventional variables such as output, inflation, and interest rates as well as fiscal variables such as taxes, spending, and debt.

Sixth, in a counterfactual exercise, we show that had the monetary policy regime of the post-Volcker era been in place pre-Volcker, inflation volatility would have been significantly 
lower: the predicted standard deviation of inflation is $1.795 \%$ compared to the actual value of $2.722 \%$. Moreover, the steep rise of inflation in the $1970 s$ would not have occurred. Therefore, a different systematic response of monetary policy to inflation would have significantly altered inflation dynamics in the pre-Volcker period.

\section{Model}

Our model is based on the prototypical New Keynesian set-up in Woodford (2003). While we consider a relatively small-scale model, we make certain extensions to the basic textbook set-up that are crucial for the issues that our paper intends to address.

We include external habit formation in consumption, partial dynamic indexation in price setting, and a time-varying inflation target in the monetary policy rule, following the recent DSGE literature (Ireland (2007), Cogley and Sbordone (2008), Cogley, Primiceri, and Sargent (2010), and Justiniano, Primiceri, and Tambalotti (2010)). We add these features because not only do they generate inertia and help capture low-frequency movements of the data, but also as emphasized by Lubik and Schorfheide (2004), they help avoid biasing our conclusion towards indeterminacy since the model can generate fairly rich dynamics. Introducing timevarying inflation target in our framework has an additional important benefit as it allows us to disentangle better two competing hypotheses on the rise in inflation in the pre-Volcker period: raised inflation target (Sargent (1999) and Cogley, Primiceri, and Sargent (2010)) as opposed to changes in propagation mechanism of fundamental shocks or sunspot fluctuations due to indeterminacy (Clarida, Gali, and Gertler (2000) and Lubik and Schorfheide (2004)).

We add to this set-up a complete description of fiscal policy. The government in our model issues one-period nominal risk-less bonds and levies lump-sum taxes to finance interest payments and exogenous streams of spending and lump-sum transfers. Similar to monetary policy, we posit an endogenous feedback rule for taxes.

\subsection{Households}

There is a continuum of households in the unit interval. Each household specializes in the supply of a particular type of labor. A household that supplies labor of type- $j$ maximizes the utility function:

$$
E_{0}\left\{\sum_{t=0}^{\infty} \beta^{t} \delta_{t}\left[\log \left(C_{t}^{j}-\eta C_{t-1}\right)-\frac{\left(H_{t}^{j}\right)^{1+\varphi}}{1+\varphi}\right]\right\},
$$

where $H_{t}^{j}$ denotes the hours of type- $j$ labor services, $C_{t}$ is aggregate consumption, and $C_{t}^{j}$ is consumption of household $j$. The parameters $\beta, \varphi$, and $\eta$ are, respectively, the discount 
factor, the inverse of the (Frisch) elasticity of labor supply, and the degree of external habit formation, while $\delta_{t}$ represents an intertemporal preference shock that follows:

$$
\delta_{t}=\delta_{t-1}^{\rho_{\delta}} \exp \left(\varepsilon_{\delta, t}\right)
$$

where $\varepsilon_{\delta, t} \sim$ i.i.d. $N\left(0, \sigma_{\delta}^{2}\right)$.

Household $j$ 's flow budget constraint is:

$$
P_{t} C_{t}^{j}+B_{t}^{j}+E_{t}\left[Q_{t, t+1} V_{t+1}^{j}\right]=W_{t}(j) H_{t}^{j}+V_{t}^{j}+R_{t-1} B_{t-1}^{j}+\Pi_{t}+S_{t}-T_{t},
$$

where $P_{t}$ is the price level, $B_{t}^{j}$ is the amount of one-period risk-less nominal government bond held by household $j, R_{t}$ is the interest rate on the bond, $W_{t}(j)$ is the competitive nominal wage rate for type- $j$ labor, $\Pi_{t}$ denotes profits of intermediate firms, and $\left(S_{t}-T_{t}\right)$ denotes government transfers net of taxes. ${ }^{9}$ In addition to the government bond, households trade at time $t$ one-period state-contingent nominal securities $V_{t+1}^{j}$ at price $Q_{t, t+1}$, and hence fully insure against idiosyncratic risk.

\subsection{Firms}

The final good $Y_{t}$, which is consumed by the government and households, is produced by perfectly competitive firms assembling intermediate goods, $Y_{t}(i)$, with a Dixit and Stiglitz (1977) production technology $Y_{t}=\left(\int_{0}^{1} Y_{t}(i)^{\frac{\theta_{t}-1}{\theta_{t}}} d i\right)^{\frac{\theta_{t}}{\theta_{t}-1}}$, where $\theta_{t}$ denotes time-varying elasticity of substitution between intermediate goods that follows $\theta_{t}=\bar{\theta}^{1-\rho_{\theta}} \theta_{t-1}^{\rho_{\theta}} \exp \left(\varepsilon_{\theta, t}\right){ }^{10}$ The corresponding price index for the final consumption good is $P_{t}=\left(\int_{0}^{1} P_{t}(i)^{1-\theta_{t}} d i\right)^{\frac{1}{1-\theta_{t}}}$, where $P_{t}(i)$ is the price of the intermediate good $i$. The optimal demand for $Y_{t}(i)$ is given by $Y_{t}(i)=\left(P_{t}(i) / P_{t}\right)^{-\theta_{t}} Y_{t}$.

Monopolistically competitive firms produce intermediate goods using the production function:

$$
Y_{t}(i)=A_{t} H_{t}(i)
$$

where $H_{t}(i)$ denotes the hours of type- $i$ labor employed by firm $i$ and $A_{t}$ represents exogenous economy-wide technological progress. The gross growth rate of technology $a_{t} \equiv A_{t} / A_{t-1}$ follows:

$$
a_{t}=\bar{a}^{1-\rho_{a}} a_{t-1}^{\rho_{a}} \exp \left(\varepsilon_{a, t}\right)
$$

where $\bar{a}$ is the steady-state value of $a_{t}$ and $\varepsilon_{a, t} \sim$ i.i.d. $N\left(0, \sigma_{a}^{2}\right)$.

\footnotetext{
${ }^{9}$ The budget constraint reflects our assumptions that each household owns an equal share of all intermediate firms and receives the same amount of net lump-sum transfers from the government.

${ }^{10} \bar{\theta}$ is the steady-state value of $\theta_{t}$.
} 
As in Calvo (1983), a firm resets its price optimally with probability $1-\alpha$ every period. Firms that do not optimize adjust their price according to the simple partial dynamic indexation rule:

$$
P_{t}(i)=P_{t-1}(i) \pi_{t-1}^{\gamma} \bar{\pi}^{1-\gamma}
$$

where $\gamma$ measures the extent of indexation and $\bar{\pi}$ is the steady-state value of the gross inflation rate $\pi_{t} \equiv P_{t} / P_{t-1}$. All optimizing firms choose a common price $P_{t}^{*}$ to maximize the present discounted value of future profits:

$$
E_{t} \sum_{k=0}^{\infty} \alpha^{k} Q_{t, t+k}\left[P_{t}^{*} X_{t, k}-\frac{W_{t+k}(i)}{A_{t+k}}\right] Y_{t+k}(i),
$$

where

$$
X_{t, k} \equiv\left\{\begin{array}{c}
\left(\pi_{t} \pi_{t+1} \cdots \pi_{t+k-1}\right)^{\gamma} \bar{\pi}^{(1-\gamma) k}, \quad k \geq 1 \\
1, \quad k=0
\end{array}\right.
$$

\subsection{Government}

\subsubsection{Budget constraint}

Each period, the government collects lump-sum tax revenues $T_{t}$ and issues one-period nominal bonds $B_{t}$ to finance its consumption $G_{t}$, lump-sum transfer payments $S_{t}$, and interest payments. ${ }^{11}$ Accordingly, the flow budget constraint is given by:

$$
\frac{B_{t}}{P_{t}}=R_{t-1} \frac{B_{t-1}}{P_{t}}+G_{t}-\left(T_{t}-S_{t}\right)
$$

which can be rewritten by expressing fiscal variables as ratios to output:

$$
b_{t}=R_{t-1} b_{t-1} \frac{1}{\pi_{t}} \frac{Y_{t-1}}{Y_{t}}+g_{t}-\tau_{t}+s_{t}
$$

where $b_{t}=B_{t} / P_{t} Y_{t}, g_{t}=G_{t} / Y_{t}, \tau_{t}=T_{t} / Y_{t}$, and $s_{t}=S_{t} / Y_{t}$.

Government spending and transfers follow exogenous processes given by:

$$
\begin{aligned}
& g_{t}=\left(1-\rho_{g}\right) \bar{g}+\rho_{g} g_{t-1}+\varepsilon_{g, t}, \\
& s_{t}=\left(1-\rho_{s}\right) \bar{s}+\rho_{s} s_{t-1}+\varepsilon_{s, t},
\end{aligned}
$$

where $\bar{g}$ and $\bar{s}$ are the steady-state values of $g_{t}$ and $s_{t}$ respectively, $\varepsilon_{g, t} \sim$ i.i.d. $N\left(0, \sigma_{g}^{2}\right)$, and

\footnotetext{
${ }^{11}$ It might be worthwhile to relax the restriction of one-period governemnt bonds by allowing for long term debt as in Cochrane (2001). This will reduce inflation volatility under a passive monetary and active fiscal policy regime.
} 
$\varepsilon_{s, t} \sim$ i.i.d. $N\left(0, \sigma_{s}^{2}\right)$.

\subsubsection{Monetary policy}

The central bank sets the nominal interest rate according to a Taylor-type rule:

$$
\frac{R_{t}}{\bar{R}}=\left(\frac{R_{t-1}}{\bar{R}}\right)^{\rho_{R}}\left[\left(\frac{\pi_{t}}{\pi_{t}^{*}}\right)^{\phi_{\pi}}\left(\frac{Y_{t}}{Y_{t}^{*}}\right)^{\phi_{Y}}\right]^{1-\rho_{R}} \exp \left(\varepsilon_{R, t}\right)
$$

which features interest rate smoothing and systematic responses to deviation of output from its natural level $Y_{t}^{*}$ and deviation of inflation from a time-varying target $\pi_{t}^{*} \cdot{ }^{12} \bar{R}$ is the steady-state value of $R_{t}$ and the non-systematic monetary policy shock $\varepsilon_{R, t}$ is assumed to follow i.i.d. $N\left(0, \sigma_{R}^{2}\right)$. The inflation target evolves exogenously as:

$$
\pi_{t}^{*}=\bar{\pi}^{1-\rho_{\pi}}\left(\pi_{t-1}^{*}\right)^{\rho_{\pi}} \exp \left(\varepsilon_{\pi, t}\right)
$$

where $\varepsilon_{\pi, t} \sim$ i.i.d. $N\left(0, \sigma_{\pi}^{2}\right)$.

\subsubsection{Fiscal policy}

We assume a parsimonious fiscal policy rule that somewhat resembles the interest rate rule (1). ${ }^{13}$ The fiscal authority sets the tax revenues-to-output ratio according to the fiscal rule:

$$
\frac{\tau_{t}}{\bar{\tau}}=\left(\frac{\tau_{t-1}}{\bar{\tau}}\right)^{\rho_{\tau}}\left[\left(\frac{b_{t-1}}{b_{t-1}^{*}}\right)^{\tilde{\psi}_{b}}\left(\frac{Y_{t}}{Y_{t}^{*}}\right)^{\tilde{\psi}_{Y}}\left(\frac{g_{t}}{\bar{g}}\right)^{\tilde{\psi}_{g}}\right]^{1-\rho_{\tau}} \exp \left(\tilde{\varepsilon}_{\tau, t}\right)
$$

which features tax smoothing and systematic responses to deviation of lagged debt-to-output ratio from a time varying target $b_{t-1}^{*}$, deviation of output from its natural level, and deviation of government spending-to-output ratio from its steady state level. $\bar{\tau}$ is the steady-state value of $\tau_{t}$ and the non-systematic fiscal policy shock $\tilde{\varepsilon}_{\tau, t}$ is assumed to follow i.i.d. $N\left(0, \tilde{\sigma}_{\tau}^{2}\right)$. Similarly to the inflation target, the debt-to-output ratio target evolves exogenously as:

$$
b_{t}^{*}=\left(1-\rho_{b}\right) \bar{b}+\rho_{b} b_{t-1}^{*}+\varepsilon_{b, t},
$$

where $\bar{b}$ is the steady-state value of $b_{t}$ and $\varepsilon_{b, t} \sim$ i.i.d. $N\left(0, \sigma_{b}^{2}\right)$.

\footnotetext{
${ }^{12}$ The natural level of output is the output that would prevail under flexible prices and in the absence of the shocks $\theta_{t}$.

${ }^{13}$ The specification is similar to that in Davig and Leeper (2011).
} 


\subsection{Equilibrium, policy regimes, and determinacy}

Equilibrium is characterized by the prices and quantities that satisfy the households' and firms' optimality conditions, the government budget constraint, monetary and fiscal policy rules, and the clearing conditions for the product, labor, and asset markets:

$$
\begin{gathered}
\int_{0}^{1} C_{t}^{j} d j+G_{t}=Y_{t}, \\
H_{t}(j)=H_{t}^{j}, \\
\int_{0}^{1} V_{t}^{j} d j=0 \\
\int_{0}^{1} B_{t}^{j} d j=B_{t} .
\end{gathered}
$$

Note that $C_{t}^{j}=C_{t}$ due to the complete market assumption. The details of the optimality conditions and the equilibrium are provided in the Appendix.

We use approximation methods to solve for equilibrium: we detrend variables on the balanced growth path by normalizing by $A_{t}$ and obtain a first-order approximation to the equilibrium conditions around the non-stochastic steady state. ${ }^{14}$ The linearized equations are standard and are provided in the Appendix. Here we describe the linearized policy rules and the government budget constraint to facilitate our discussion of determinacy and policy regimes:

$$
\begin{aligned}
& \hat{R}_{t}=\rho_{R} \hat{R}_{t-1}+\left(1-\rho_{R}\right)\left[\phi_{\pi}\left(\hat{\pi}_{t}-\hat{\pi}_{t}^{*}\right)+\phi_{Y}\left(\widehat{\tilde{Y}}_{t}-\widehat{\tilde{Y}}_{t}^{*}\right)\right]+\varepsilon_{R, t}, \\
& \hat{\tau}_{t}=\rho_{\tau} \hat{\tau}_{t-1}+\left(1-\rho_{\tau}\right)\left[\psi_{b}\left(\hat{b}_{t-1}-\hat{b}_{t-1}^{*}\right)+\psi_{Y}\left(\widehat{\tilde{Y}}_{t}-\widehat{\tilde{Y}}_{t}^{*}\right)+\psi_{g} \hat{g}_{t}\right]+\varepsilon_{\tau, t}, \\
& \hat{b}_{t}=\frac{1}{\beta} \hat{b}_{t-1}+\frac{\bar{b}}{\beta}\left(\hat{R}_{t-1}-\hat{\pi}_{t}-\widehat{\tilde{Y}}_{t}+\widehat{\tilde{Y}}_{t-1}-\hat{a}_{t}\right)+\hat{g}_{t}-\hat{\tau}_{t}+\hat{s}_{t} .
\end{aligned}
$$

The equilibrium of the economy will be determinate either if monetary policy is active while fiscal policy is passive (the AMPF regime) or if monetary policy is passive while fiscal policy is active (the PMAF regime). Multiple equilibria exist if both monetary and fiscal policies are passive (the PMPF regime). In our model, monetary policy is active if $\phi_{\pi}>1-\phi_{Y}\left(\frac{1-\tilde{\beta}}{\tilde{\kappa}}\right)$, where $\tilde{\beta}=\frac{\gamma+\beta}{1+\gamma \beta}$ and $\tilde{\kappa}=\frac{(1-\alpha \beta)(1-\alpha)}{\alpha(1+\varphi \theta)(1+\gamma \beta)}(1+\varphi)$, and fiscal policy is active if $\psi_{b}<\frac{1}{\beta}-1{ }^{15}$

\footnotetext{
${ }^{14}$ We denote variable $\frac{X_{t}}{A_{t}}$ by $\tilde{X}_{t}$. We define the $\log$ deviation of a variable $X_{t}$ from its steady state $\bar{X}$ as $\hat{X}_{t}=\ln X_{t}-\ln \bar{X}$, except for the four fiscal variables: $\hat{b}_{t}=b_{t}-\bar{b}, \hat{g}_{t}=g_{t}-\bar{g}, \hat{\tau}_{t}=\tau_{t}-\bar{\tau}$, and $\hat{s}_{t}=s_{t}-\bar{s}$.

${ }^{15}$ Note here that as shown in the Appendix, the relationships between the feedback parameters of the non-linear and linearized fiscal policy rules are given by: $\psi_{b} \equiv \frac{\bar{\tau}}{b} \tilde{\psi}_{b}, \psi_{Y} \equiv \bar{\tau} \tilde{\psi}_{Y}$, and $\psi_{g} \equiv \frac{\bar{\tau}}{\bar{g}} \tilde{\psi}_{g}$.
} 


\section{Empirical analysis}

\subsection{Method}

The system of linearized equations is solved for its state space representation. The solution method for linear rational expectations models of Sims (2002) is applied under determinacy. Under indeterminacy, we employ a generalization of this method proposed in Lubik and Schorfheide (2004) which expresses the solution of the model as:

$$
\mathbf{z}_{t}=\Gamma_{1}^{*}(\boldsymbol{\theta}) \mathbf{z}_{t-1}+\left\{\Gamma_{0, \varepsilon}^{*}(\boldsymbol{\theta})+\Gamma_{0, \zeta}^{*}(\boldsymbol{\theta}) M\right\} \boldsymbol{\varepsilon}_{t}+\Gamma_{0, \zeta}^{*}(\boldsymbol{\theta}) \boldsymbol{\zeta}_{t},
$$

where $\mathbf{z}_{t}$ is a vector of model variables, $\boldsymbol{\varepsilon}_{t}$ is a vector of fundamental shocks, and $\boldsymbol{\zeta}_{t}$ is a vector of sunspot shocks. The coefficient matrices $\Gamma_{1}^{*}(\boldsymbol{\theta}), \Gamma_{0, \varepsilon}^{*}(\boldsymbol{\theta})$, and $\Gamma_{0, \zeta}^{*}(\boldsymbol{\theta})$ are functions of the structural model parameters. ${ }^{16}$ The matrix $\Gamma_{0, \zeta}^{*}(\boldsymbol{\theta})=0$ under determinacy, but is not zero in general under indeterminacy. Thus indeterminacy introduces additional parameters, given by the matrix $M$ in (2), and a sunspot shock. ${ }^{17}$

With a distributional assumption on $\boldsymbol{\zeta}_{t}$ (and $\varepsilon_{t}$ ), one can construct the likelihood of the solution of the model using the Kalman filter. We use conventional Bayesian methods widely used in the DSGE literature to fit the model to the data. Since it is difficult to characterize analytically the posterior distribution of the structural parameters, we use a Markov Chain Monte Carlo simulation. We first find a mode of the posterior density numerically using csminwel by Christopher A. Sims. Then we use a random-walk Metropolis algorithm to draw a sample from the posterior distribution. The proposal density of the random-walk Metropolis algorithm is a Normal distribution whose mean is the previous successful draw and variance is the inverse of the negative Hessian at the posterior mode found before the simulation. The variance of the proposal density is scaled to achieve an acceptance rate of around 30\%. For details of the random-walk Metropolis algorithm, see An and Schorfheide (2007). For model comparison purposes, marginal likelihoods are estimated using the modified harmonic mean estimator by Geweke (1999).

\subsection{Data}

We use six key quarterly U.S. data as observables: per-capita output growth, annualized inflation, annualized federal funds rate, tax revenues-to-output ratio, market value of government debt-to-output ratio, and government spending-to-output ratio. A detailed description of the data is in the Appendix. To make our results comparable to those of Lubik and Schorfheide

\footnotetext{
${ }^{16} \boldsymbol{\theta}$ is a vector of model parameters.

${ }^{17}$ Appendix provides a more detailed discussion of the solution method.
} 
(2004), we estimate the model over two samples: a pre-Volcker sample from 1960:Q1 to 1979:Q2 and a post-Volcker sample from 1982:Q4 to 2008:Q2. In particular, we drop the Volcker disinflation period.

The corresponding measurement equations are given by:

$$
\begin{aligned}
100 \times \Delta \log (\text { Real per capita output }) & =\hat{\tilde{Y}}_{t}-\widehat{\tilde{Y}}_{t-1}+\hat{a}_{t}+a \\
\text { Annualized inflation }(\%) & =4 \hat{\pi}_{t}+4 \pi \\
\text { Annualized interest rates }(\%) & =4 \hat{R}_{t}+4(a+\pi+\mu) \\
\frac{\text { Nominal tax revenue }}{\text { Nominal output }}(\%) & =\hat{\tau}_{t}+100 \bar{\tau} \\
\frac{\text { Nominal government debt }}{\text { Nominal output }}(\%) & =\hat{b}_{t}+100 \bar{b} \\
\frac{\text { Nominal government purchases }}{\text { Nominal output }}(\%) & =\hat{g}_{t}+100 \bar{g}
\end{aligned}
$$

where $a \equiv 100(\bar{a}-1), \pi \equiv 100(\bar{\pi}-1)$, and $\mu \equiv 100\left(\beta^{-1}-1\right)$.

\subsection{Prior distributions}

We calibrate $\varphi=1$ and $\bar{\theta}=8 .{ }^{18}$ We also calibrate $\rho_{\pi^{*}}$ and $\rho_{b^{*}}$ to 0.995 to restrict the role for time-varying policy targets to that of explaining low frequency behavior of the data only. For all the other parameters that we estimate, the priors we use are in Table 1. For the mean value of observables and the technology growth rate, we use sample specific priors. We use the same priors across the two sample periods for all other parameters. Most of the priors that we use are standard in the literature. We discuss in detail two sets of priors that are unique to our analysis.

The first are those related to the policy rules. We impose each policy regime by reparameterizing two key policy parameters in the monetary and fiscal rules: $\phi_{\pi}$ and $\psi_{b}$. Denote the boundaries for active and passive policies by $\Phi^{M}(\boldsymbol{\theta}) \equiv 1-\phi_{Y}\left(\frac{1-\tilde{\beta}}{\tilde{\kappa}}\right)$ and $\Phi^{F}(\boldsymbol{\theta}) \equiv$ $\frac{1}{\beta}-1$ respectively. Then let:

$$
\begin{aligned}
& \phi_{\pi}=\Phi^{M}(\boldsymbol{\theta})+\phi_{\pi}^{*} ; \psi_{b}=\Phi^{F}(\boldsymbol{\theta})+\psi_{b}^{*}, \\
& \phi_{\pi}=\Phi^{M}(\boldsymbol{\theta})-\phi_{\pi}^{*} ; \psi_{b}=\Phi^{F}(\boldsymbol{\theta})-\psi_{b}^{*}, \\
& \phi_{\pi}=\Phi^{M}(\boldsymbol{\theta})-\phi_{\pi}^{*} ; \psi_{b}=\Phi^{F}(\boldsymbol{\theta})+\psi_{b}^{*},
\end{aligned}
$$

for the AMPF, PMAF, and PMPF regimes respectively.

\footnotetext{
${ }^{18} \bar{\theta}$ and $\varphi$ are not seperately identified from $\alpha$.
} 
The newly introduced parameters, $\phi_{\pi}^{*}$ and $\psi_{b}^{*}$, are assumed positive by specifying a gamma prior distribution with means 0.5 and 0.05 and standard deviations 0.2 and 0.04 , respectively. This reparametarization thus ensures that we completely impose a particular policy regime during estimation. The implied $90 \%$ prior probability interval for $\phi_{\pi}$ is $(1.189,1.811)$ under $\mathrm{AM}$ and $(0.185,0.811)$ under PM while for $\psi_{b}$ it is $(0.003,0.107)$ under PF and $(-0.102,0.003)$ under AF (see Table 2). ${ }^{19}$

The second are those related to the case of indeterminacy. As mentioned above, indeterminacy introduces additional parameters, given by the matrix $M$ in (2). We try a few alternative specifications for the priors of those parameters. In the first specification, we follow Lubik and Schorfheide (2004) and set the prior mean of the additional parameters in $M$ so that the impact impulse responses of endogenous variables to fundamental shocks are as close as possible across the boundary between the determinacy and indeterminacy region. Our DSGE model however, exhibits very different dynamics under determinacy and indeterminacy because of the monetary and fiscal policy interactions. We thus do not find it very appealing to require that the DSGE model have similar dynamics across the determinacy and indeterminacy boundary. In the second specification, we therefore set the prior mean of $M$ to zero. Since $\Gamma_{0, \varepsilon}^{*}(\boldsymbol{\theta})$ and $\Gamma_{0, \zeta}^{*}(\boldsymbol{\theta})$ in (2) are orthogonal, this specification implies that the initial impact of fundamental shocks is orthogonal to that of sunspot shocks at the prior mean. In addition, we employ a quite diffuse prior for $M$ to check the sensitivity of our results. In the remainder of this paper, we report the results based on the second specification. Our results however, are completely robust across the different specifications.

\subsection{Model comparison}

We use marginal likelihoods across different policy regime specifications to compare model fit. As Table 3 shows, the data favors the PMPF regime pre-Volcker, which implies indeterminacy, and the AMPF regime post-Volcker. ${ }^{20}$ In this regard, our finding is in line with Lubik and Schorfheide (2004). As we will show below however, the propagation mechanism under our PMPF regime is substantively different from that under indeterminacy in their paper. This underscores the importance of a complete specification of monetary and fiscal policies and the inclusion of fiscal variables in model estimation.

\footnotetext{
${ }^{19}$ These intervals cover the range of values found in the literature, for example, Davig and Leeper (2011). Note that we restrict the parameter space of $\phi_{\pi}^{*}$ so that $\phi_{\pi}$ is always positive.

${ }^{20}$ Note that if we had restricted the estimation to determinacy, then PMAF fits the data better than AMPF pre-Volcker. This result is in contrast with that of Traum and Yang (2011), who use a different model and data. In future, it will be interesting to fully explore the main reasons for this difference.
} 


\subsection{Posterior estimates}

In Table 4 we present the posterior estimates of the best fitting models for the two sample periods: PMPF for pre-Volcker and AMPF for post-Volcker. As to be expected, the estimates of some key policy parameters are different: the implied estimate of the posterior mean for $\phi_{\pi}$ is 0.188 pre-Volcker and 1.299 post-Volcker while for $\psi_{b}$ it is 0.094 pre-Volcker and 0.091 post-Volcker. The $90 \%$ posterior probability interval for $\phi_{\pi}$ is $(0,0.354)$ pre-Volcker and $(0.922,1.680)$ post-Volcker while for $\psi_{b}$ it is $(0.040,0.146)$ pre-Volcker and $(0.024,0.168)$ post-Volcker.

In addition to the feedback parameters, we also find that the volatility of the two shocks in the monetary policy rule, $\varepsilon_{\pi, t}$ and $\varepsilon_{R, t}$, changed significantly across the sample periods. The standard deviation of the shock to the inflation target dropped from 0.060 to 0.037 while the volatility of the monetary policy shock fell from 0.167 to 0.108 . This finding is in line with that of Cogley, Primiceri, and Sargent (2010), even though our policy regime in the pre-Volcker period is different from theirs and unlike them, we include fiscal variables in our estimation. In contrast to shocks in the monetary policy reaction function, there was no substantial change in the volatility of the two shocks in the fiscal policy rule, $\varepsilon_{b, t}$ and $\varepsilon_{\tau, t}$, after the Volcker disinflation.

With respect to the structural model parameters, we find that the degree of price stickiness increased in the post-Volcker period compared to the pre-Volcker period, while the degree of price indexation declined. These findings are consistent with results from a similar subsample estimation exercise in Smets and Wouters (2007). We thus again show that these results of the literature are robust to the inclusion of a completely specified fiscal rule as well as fiscal variables in model estimation. In addition, the degree of habit formation $\eta$ is lower pre-Volcker than post-Volcker, which again confirms the finding of previous studies such as Smets and Wouters (2007) and Cogley, Primiceri, and Sargent (2010). Our estimate in the pre-Volcker period, 0.217, however, is smaller than those obtained in the previous studies because under PMPF, the model can generate fairly persistent dynamics relative to under AMPF without requiring a high level of habit formation. ${ }^{21}$

In terms of exogenous processes not related to the policy reaction functions, the standard deviation of most shocks decreased in the post-Volcker compared to the pre-Volcker period. For example, the standard deviation of the cost-push shock $\hat{u}_{t}$ declined by a quantitatively important amount, which probably reflects less significant oil price shocks in the post-Volcker period. ${ }^{22}$ The only exception to this is the demand shock $\hat{d}_{t}$ which became more volatile in

\footnotetext{
${ }^{21}$ When we imposed AMPF pre-Volcker, the esimate of $\eta$ is 0.750 and not significantly different from the estimate in the post-Volcker period.

${ }^{22}$ Similar to Smets and Wouters (2007), we normalized some shocks. Specifically, we estimated $\hat{d}_{t} \equiv$ $\left(1-\rho_{\delta}\right) \hat{\delta}_{t}$ and $\hat{u}_{t} \equiv-\frac{(1-\alpha \beta)(1-\alpha)}{\alpha(1+\varphi \theta)(1+\gamma \beta)} \frac{1}{\theta-1} \hat{\theta}_{t}$. See the Appendix for the model equations used in our estimation.
} 
the post-Volcker period. In terms of the persistence parameter, while it decreased for most shocks, it increased quite a bit for the technology shock $\hat{a}_{t}$ and increased marginally for the government spending shock $\hat{g}_{t}$.

\subsection{Propagation of shocks}

\subsubsection{Transmission mechanism of policy}

In Figures $1-4$ we present impulse responses to monetary and fiscal policy shocks in the two sample periods. Our main finding is that for the best fitting models, PMPF pre-Volcker and AMPF post-Volcker, the monetary and fiscal policy transmission mechanisms are substantially different. In particular, we find that the monetary and fiscal policy transmission mechanisms in our estimated PMPF model in the pre-Volcker era are similar to those that would prevail under PMAF in many important dimensions.

For the best fitting model pre-Volcker, as shown in Figure 1, a monetary contraction (i.e. an unanticipated increase in the nominal interest rate) leads to an increase, not a decrease, in output and inflation. This result is in line with the prediction of the FTPL, which under determinacy would be operative under PMAF. FTPL predicts an increase in spending following an interest rate increase due to a positive wealth effect, which then increases output and inflation, as shown in Figure 1. Thus our results provide a model based interpretation to the "price puzzle" of the identified VAR literature: the tendency of inflation to increase on impact following a contractionary monetary policy shock. Hanson (2004) in a comprehensive study showed that this "price puzzle" seems to be a feature only of the pre-Volcker period and not for the entire post-War U.S. data, which is consistent with our results.

In addition, pre-Volcker, the impulse responses to various fiscal shocks resemble those predicted by the FTPL. For example, an exogenous increase in the lump-sum tax-to-output ratio produces a recession, decreasing output and inflation as shown in Figure 3, an event one would not observe under conventional AMPF. The interest rate decreases as well, only weakly responding to lower inflation due to passive monetary policy. This is indeed the prediction of the FTPL: an increase in taxes leads to a negative wealth effect, which decreases spending and thereby inflation and output. This is shown clearly in Figure 3. We thus find that our estimated best-fitting model pre-Volcker, a PMPF regime, mimics a PMAF regime in important dimensions, even though it is not technically one where the FTPL has to be operative for sure. ${ }^{23}$

While the pre-Volcker U.S. economy was characterized by PMPF, it was under a AMPF regime post-Volcker. Accordingly, and unlike the pre-Volcker era, the impulse responses are in

\footnotetext{
${ }^{23}$ Note that although the PMPF regime mimics the PMAF regime in the aforementioned dimensions, it is different in other dimensions and thus is well identified
} 
line with the predictions of standard monetary models: Figure 2 shows that an unanticipated increase in the nominal interest rate leads to a decrease, not an increase, in inflation. In addition, as Figure 4 makes clear, exogenous adjustments in tax revenues do not affect output, inflation, and the interest rate, a conventional "Ricardian" equivalence result.

Moreover, Figures 2 and 4 show that post-Volcker, the PMPF model also produces quite similar dynamics to AMPF. For example, as shown in Figure 2, the impulse responses to a monetary contraction are quite similar between the two regimes, although the error bands are much wider under PMPF. Similarly, Figure 4 illustrates that the two regimes have similar predictions also for the propagation of fiscal shocks, since an unanticipated increase in taxto-output ratio has no meaningful impacts on output, inflation and the interest rate while reducing debt-to-output ratio under both the regimes. While the dynamics are similar, since the PMPF regime involves many more estimated parameters, it is not favored over the AMPF regime in our Bayesian model comparison.

We emphasize that our results for the pre-Volcker period are thus data-driven, and not hard-wired into our model specification and estimation. Depending on how agents form beliefs, as shown above, the model under PMPF can generate a wide range of dynamics, including those that resemble the outcomes under AMPF or PMAF or neither. By characterizing the full set of indeterminate beliefs with the additional parameters in $M$ and the sunspot shocks, we construct the distribution of the agent's beliefs conditional on the data. In doing so, we find, for example, that the pre-Volcker data favors the agents' beliefs that inflation would increase on impact (and afterwards) in response to monetary contractions. Under PMPF post-Volcker however, our estimates imply that the agents did not believe that inflation would increase in response to interest rate increases. Similarly, the pre-Volcker data favors the agents' beliefs that inflation would decrease on impact (and afterwards) in response to fiscal contractions. Under PMPF post-Volcker however, our estimates imply that the agents believed that inflation would increase in response to lump-sum tax increases on average. However, since the error band is quite wide and covers zero, the effect is not significant.

To make these mechanisms even more transparent, in Figure 5, we decompose the impulse responses to monetary policy shocks under PMPF in the two time periods into two components as given by $(2)$ : the part due to $\Gamma_{0, \varepsilon}^{*}(\boldsymbol{\theta})$ (the determined component) and that due to $\Gamma_{0, \zeta}^{*}(\boldsymbol{\theta}) M$ (the undetermined component that captures self-fulfilling beliefs). As is clear, while pre-Volcker, the self-fulfilling beliefs captured by the undetermined component imply an increase in inflation following a monetary contraction, post-Volcker, they imply a decrease in inflation. Similarly, in Figure 6, we decompose the impulse responses to fiscal policy shocks under PMPF in the two time periods into the determined and undetermined components. As is clear, while pre-Volcker, the self-fulfilling beliefs captured by the undetermined component 
imply a decrease in inflation following a fiscal contraction, post-Volcker, they imply an increase in inflation.

\subsubsection{Variance decomposition}

Role of random component of policy We showed above that transmission mechanisms of monetary and fiscal policies are substantially different in the two time-periods. We next assess how important were the random components in policies in explaining variations in inflation and output. Variance decomposition results, as given in Tables 5 and 6 , show that in both the time-periods and at both the short and long-run, unanticipated shifts in monetary and fiscal policies play only a minor role in explaining the dynamics of inflation and output. ${ }^{24}$

For example, for inflation, pre-Volcker, monetary and fiscal policy shocks explain less than $10 \%$ of the variation at both horizons. In particular, pre-Volcker, lump-sum tax shocks explain $3.1 \%$ of inflation variation in the short-run and $1.3 \%$ in the long-run. These effects, while smaller, are roughly the same order of magnitude as those of monetary policy shocks, which explain $8.1 \%$ of inflation variation in the short-run and $4.6 \%$ in the long-run. Post-Volcker, while the fiscal policy shock explains no variation at either horizon because the prevailing regime is AMPF, the monetary policy shock also is estimated to explain basically no variation at either horizon.

For output growth, pre-Volcker, monetary policy shocks explain around $1.6 \%$ while fiscal policy shocks explain around $6.0 \%$ of the variation in both the short and long-run. PostVolcker, the monetary shock explains around $2.5 \%$ of the variation at both horizons while fiscal policy shocks explain basically no variation in output growth. Our result that random variations in monetary policy do not explain much of the fluctuations in inflation and output is consistent with the results in the identified VAR literature, for example, Sims and Zha (2006a). That the same conclusion also holds for random variations in fiscal policy, given by unanticipated movements in taxes, is completely new to the literature.

Role of time-varying inflation target We next assess the role of time-varying inflation target in explaining inflation dynamics, in particular the rise in inflation in the pre-Volcker period. In the recent DSGE literature, a consensus finding has emerged that the long-run variation in inflation is explained mostly by shocks to the inflation target in the monetary reaction function. For example, Cogley, Primiceri, and Sargent (2010) show that both preand post-Volcker, smoothed values of the inflation target shock recovered from estimation track actual inflation remarkably well. In contrast, we find that pre-Volcker, as opposed to post-Volcker, variations in the inflation target do not explain low-frequency movements in

\footnotetext{
${ }^{24}$ We focus on a 4 and 40 quarter horizon in our variance decomposition results.
} 
inflation.

Table 5 clearly shows that while we find a similar result to Cogley, Primiceri, and Sargent (2010) in the post-Volcker period, where the inflation target shock accounts for $81.1 \%$ of the long-run variation in inflation, our results are quite different in the pre-Volcker era, where the inflation target shock explains only $5.5 \%$ of the long-run variation in inflation. We make this result also clear in Fig. 7, which plots smoothed inflation target shocks recovered from the estimation of the model in the two time-periods under various policy regime combinations. While inflation target shock tracks inflation well under an AMPF regime, this correspondence weakens substantially under either PMPF or PMAF.

The major reason for this difference is that we explicitly allow for the possibility of indeterminacy while estimating our model that features both monetary and fiscal policy. When the regime is active monetary and passive fiscal policy, as is the implicit assumption in Cogley, Primiceri, and Sargent (2010) for both the time-periods, then changes in inflation target do explain inflation in the long-run since monetary policy fully controls inflation dynamics. Our best-fitting estimated model in the pre-Volcker features indeterminacy due to passive monetary policy, however. In this case, consider an increase in the inflation target. This, through the central bank reaction function, does tend to decrease the interest rate. A decrease in interest rate in this model though, as we pointed out above, tends to decrease inflation. Thus, inflation target movements do not track actual inflation in the long-run. Figure 7 thus makes clear how the role of time-varying inflation target in tracking the low-frequency movement in inflation depends crucially on the monetary and fiscal policy regime in place.

Inflation, output, and debt dynamics We now address which shocks were major drivers of the dynamics of the three key variables in our model: inflation, output, and debt-to-output ratio. Our main finding is that the primary sources of short and long-run variations in inflation, output, and debt are different in the two time periods as the propagation mechanism of shocks varies because of the change in monetary policy stances.

As mentioned above, and shown clearly in Table 5, post-Volcker, low frequency movement in inflation is explained mostly by changes in the inflation target. The high frequency movement is mostly explained by mark-up shocks, which is also a standard result in the literature. In the pre-Volcker period, in contrast, the role of mark-up shocks gets reduced in the short-run while that of technology and demand shocks increases. Moreover, demand and technology shocks also explain much of the variation in the long-run along with a non-trivial role for mark-up shocks. The important role of mark-up shocks at both horizons in the pre-Volcker period is not surprising given the oil price shocks of the 1970s. Moreover, in the pre-Volcker period, since the monetary policy regime was passive, demand shocks that would typically be stabilized under active monetary policy end up influencing inflation dynamics significantly. 
To emphasize this role of demand shocks, in Figure 8 we report results on the implied counterfactual path of inflation in the pre-Volcker period if we simulate our model using smoothed values of all other shocks except demand shocks. As is clear, the rise of inflation in the $1970 \mathrm{~s}$ is muted in that case.

For output growth, as shown in Table 6, in both periods, a combination of shocks explain variation at the two horizons, but the importance of a particular shock is quite different. For example, while pre-Volcker, markup shocks are the most important source of variation in output growth at both horizons (around 33\%), post-Volcker, they account for no variation at either horizon. Thus, according to our estimates, in the post-Volcker period, markup shocks, which lead to a trade-off between inflation and output stabilization under active monetary policy, affected inflation pre-dominantly without affecting output. Finally, government spending, technology, and demand shocks are important in both the time periods, although the role of demand shocks is much more substantial in the post-Volcker period. In fact, demand shocks explain over $50 \%$ of the variance in output growth at both horizons in this period.

It is also worth noting that for the pre-Volcker period, as Tables $5-6$ make clear, sunspot shocks introduced due to indeterminacy play a minor role in explaining the dynamics of inflation and output: they are irrelevant for inflation dynamics and explain only around $11 \%$ of the variation at both horizons for output growth. Thus indeterminacy matters in our estimated model, not because of a non-trivial role for sunspot fluctuations, but mostly because self-fulfilling beliefs regarding fundamental shocks significantly alter the propagation mechanisms in the model.

Finally, to get insights into the determinants of short- and long-run dynamics of the crucial fiscal variable, debt-to-output ratio, it is useful to consider the linearized government budget constraint which we reproduce below:

$$
\hat{b}_{t}=\frac{1}{\beta} \hat{b}_{t-1}+\frac{\bar{b}}{\beta}\left(\hat{R}_{t-1}-\hat{\pi}_{t}-\widehat{\tilde{Y}}_{t}+\widehat{\tilde{Y}}_{t-1}-\hat{a}_{t}\right)+\hat{g}_{t}-\hat{\tau}_{t}+\hat{s}_{t} .
$$

This equation makes clear that the dynamics of debt-to-output $\hat{b}_{t}$ are influenced by shocks that affect either returns $\hat{R}_{t-1}-\hat{\pi}_{t}$, output growth $\widehat{\tilde{Y}}_{t}-\widehat{\tilde{Y}}_{t-1}+\hat{a}_{t}$, or primary deficit $\hat{g}_{t}-\hat{\tau}_{t}+\hat{s}_{t}$. In both the time-periods, as Table 7 shows, the short-run variation is explained mostly by the exogenous transfer shock (60.8 and 73.6\% respectively). Pre-Volcker, the remaining variation is explained by mark-up and technology shocks due to their effects on inflation, while postVolcker, it is explained by the fiscal policy shock due to its effect on tax revenues.

In the long-run, a combination of shocks are important, but the relative contribution of these shocks across the two eras are quite different. In both the periods, government spending shocks account for an important portion of the variation. Moreover, in the post-Volcker period, transfer and fiscal policy shocks are also important drivers of long-run variation in $\hat{b}_{t}$. Finally, 
pre-Volcker, demand, mark-up, and technology shocks account for substantial variation in the long-run while post-Volcker, the inflation target shock explains a non-trivial portion of the variation. These roles for the shocks arise because, as explained above, they are important drivers of long-run variation in inflation in the respective time-periods.

\subsubsection{Role of policy in the rise of inflation}

With the estimated structural model parameters at hand, we now conduct a counterfactual exercise. We assess the model implied path of inflation, output, and debt-to-output ratio had the post-Volcker monetary policy regime been in place in the pre-Volcker period. In particular, with the estimated model parameters and smoothed shocks of the pre-Volcker period, we simulate our model by making two changes: shutting down the shocks $\hat{\pi}_{t}^{*}$ and $\varepsilon_{R, t}$ while using the estimate of $\phi_{\pi}$ from the post-Volcker period. ${ }^{25}$

First, we find that the model implied standard deviation of inflation is $1.795 \%$, which is substantially lower than the actual value of $2.722 \%$. Moreover, Figure 9, where we plot the model implied path of inflation together with actual inflation, makes clear that under this monetary policy regime, the rise of inflation in the $1970 \mathrm{~s}$ would have been avoided. Thus, our counterfactual exercise suggests that a change in the systematic response of monetary policy would have mattered greatly for inflation dynamics in the pre-Volcker era. Second, we find that while output growth would not have been quantitatively different, the debt-to-output ratio would have been higher in the $1970 \mathrm{~s}$. The higher debt-to-output ratio is a result of lower implied inflation, which negates its role in debt stabilization. Figure 9, where we plot the model implied path of output growth and debt-to-output ratio together with their actual paths, depicts these results clearly.

\section{Conclusion}

In this paper we have addressed some long-standing questions in macroeconomics using an estimated DSGE model that has a complete description of both monetary and fiscal policies. Our main result is that the monetary and fiscal policy regime combination in place has mattered historically for a host of issues: the prevalence of equilibrium indeterminacy, the transmission mechanism of monetary and fiscal policy, and the major sources of variation in output, inflation, and government debt. That is, we find the nature of the systematic response

\footnotetext{
${ }^{25}$ Note here that we only change $\phi_{\pi}$ and in particular, keep the fiscal parameters the same as the estimated values. Moreover, while we shut down $\hat{\pi}_{t}^{*}$ and $\varepsilon_{R, t}$, that does not influence our results. In other words, under PMPF in the pre-Volcker regime, inflation dynamics with and without these shocks are virtually identical, as our earlier variance decomposition results make clear.
} 
of policy to the state of the economy to be paramount in the propagation mechanism of both policy and non-policy shocks.

In future work, we plan to conduct several robustness exercises and also extend our methodology. Given Sims and Zha (2006b)'s findings using an identified VAR that including a monetary aggregate in the monetary policy rule affects inference regarding indeterminacy in the pre-Volcker period, we want to assess if this alteration to the monetary policy rule influences our model comparison results. Moreover, we plan to make our fiscal policy specification richer by allowing for countercyclical government spending, as emphasized recently by Cúrdia and Reis (2011).

More generally, it will be interesting to extend our methodology on two fronts. First, we can allow for time-varying volatility of shocks in our estimated DSGE model, along the lines of Justiniano and Primiceri (2008). Second, extending our sub-sample analysis, we can estimate a DSGE model with recurring regime switching in both monetary and fiscal policies, using the methodology provided in Farmer, Waggoner, and Zha (2011). 


\section{References}

[1] Aiyagari, S. Rao and Mark Gertler. 1985. "The Backing of Government Bonds and Monetarism." Journal of Monetary Economics, 16(1): 19-44.

[2] An, Sungbae and Frank Schorfheide. 2007. "Bayesian Analysis of DSGE Models." Econometric Reviews, 26(2-4): 113-72.

[3] Bhattarai, Saroj, Jae Won Lee, and Woong Yong Park. 2012. "Monetary-Fiscal Policy Interactions and Indeterminacy in Post-War U.S. Data." Forthcoming in American Economic Review, Papers and Proceedings.

[4] Bianchi, Francesco and Cosmin Ilut. 2012. "Monetary/Fiscal Policy Mix and Agents' Beliefs." Unpublished.

[5] Calvo, Guillermo. 1983. "Staggered Prices in a Utility-Maximizing Framework." Journal of Monetary Economics, 12: 983-998.

[6] Canzoneri, Matthew, Robert Cumby, and Behzad Diba. 2011. "The Interaction Between Monetary and Fiscal Policy." In Handbook of Monetary Economics, Vol. 3B, ed. Benjamin M. Friedman and Michael Woodford, 935-99. Amsterdam: Elsevier Science, NorthHolland.

[7] Clarida, Richard, Jordi Galí, and Mark Gertler. 2000. "Monetary Policy Rules And Macroeconomic Stability: Evidence And Some Theory." Quarterly Journal of Economics, 115(1): $147-180$.

[8] Cochrane, John H. 2001. "Long-term Debt and Optimal Policy in the Fiscal Theory of the Price Level." Econometrica, 69(1): 69-116.

[9] Cogley, Timothy, Giorgio E. Primiceri, and Thomas J. Sargent. 2010. "Inflation-Gap Persistence in the U.S." American Economic Journal: Macroeconomics, 2(1): 43-69.

[10] Cogley, Timothy and Argia M. Sbordone. 2008. "Trend Inflation, Indexation, and Inflation Persistence in the New Keynesian Phillips Curve." American Economic Review, 98(5): 2101-26.

[11] Cúrdia, Vasco and Ricardo Reis. 2010. "Correlated Disturbances and U.S. Business Cycles." NBER Working Paper 15774.

[12] Davig, Troy and Eric M. Leeper. 2011. "Monetary-Fiscal Policy Interactions and Fiscal Stimulus." European Economic Review, 55(2): 211-27. 
[13] Dixit, Avinash K. and Joseph E. Stiglitz. 1977. "Monopolistic Competition and Optimum Product Diversity." American Economic Review, 67: 297-308.

[14] Farmer, Roger E. A., Daniel F. Waggoner, and Tao Zha. 2011. "Minimal State Variables Solutions to Markov-switching Rational Expectations Models." Journal of Economic Dynamics and Control, 35(12): 2150-66.

[15] Geweke, John. 1999. "Using Simulation Methods for Bayesian Econometric Models: Inference, Development, and Communication." Econometric Reviews, 18(1): 1-73.

[16] Hanson, Michael S. 2004. "The "Price Puzzle" Reconsidered." Journal of Monetary Economics, 51(7): 1385-1413.

[17] Ireland, Peter N. 2007. "Changes in the Federal Reserve's Inflation Target: Causes and Consequences." Journal of Money, Credit and Banking, 39(8): 1851-1882.

[18] Justiniano, Alejandro and Giorgio E. Primiceri. 2008. "The Time-Varying Volatility of Macroeconomic Fluctuations." American Economic Review, 98(3): 604-41.

[19] Justiniano, Alejandro, Giorgio E. Primiceri, and Andrea Tambalotti. 2010. "Investment Shocks and Business Cycles." Journal of Monetary Economics, 57(2): 132-145.

[20] Leeper, Eric M. 1991. "Equilibria under 'Active' and 'Passive' Monetary and Fiscal Policies." Journal of Monetary Economics, 27(1): 129-47.

[21] Lubik, Thomas A. and Frank Schorfheide. 2004. "Testing for Indeterminacy: An Application to U.S. Monetary Policy." American Economic Review, 94(1): 190-217.

[22] Sargent, Thomas J. 1999. The Conquest of American Inflation. Princeton, NJ: Princeton University Press.

[23] Sargent, Thomas J. and Neil Wallace. 1981. "Some Unpleasant Monetarist Arithmetic." Quarterly Review, Federal Reserve Bank of Minneapolis, 5(3): 1-17.

[24] Shapiro, Matthew and Mark Watson. 1988. "Sources of Business Cycle Fluctuations." in NBER Macroeconomics Annual, Vol. 3, ed. Stanley Fischer, 111-56. Cambridge, MA: MIT Press.

[25] Sims, Christopher A. 1992. "Interpreting the Macroeconomic Time Series Facts: The Effects of Monetary Policy." European Economic Review, 36(5): 975-1000.

[26] Sims, Christopher A. 1994. "A Simple Model for Study of the Determination of the Price Level and the Interaction of Monetary and Fiscal Policy." Economic Theory, 4(3): 381-99. 
[27] Sims, Christopher A. 2002. "Solving Linear Rational Expectations Models." Computational Economics, 20(1-2): 1-20.

[28] Sims, Christopher A. 2011. "Stepping on a Rake: The Role of Fiscal Policy in the Inflation of the 1970s." European Economic Review, 55(1): 48-56.

[29] Sims, Christopher A. and Tao Zha. 2006a. "Does Monetary Policy Generate Recessions?." Macroeconomic Dynamics, 39(4): 949-68.

[30] Sims, Christopher A. and Tao Zha. 2006b. "Were There Regime Switches in U.S. Monetary Policy?." American Economic Review, 96(1): 54-81.

[31] Smets, Frank R. and Raf Wouters. 2007. "Shocks and Frictions in U.S. Business Cycles: A Bayesian DSGE Approach." American Economic Review, 97(3): 586-606.

[32] Traum, Nora and Shu-Chun S. Yang. 2011. "Monetary and Fiscal Policy Interactions in the Post-war U.S." European Economic Review, 55(1): 140-64.

[33] Woodford, Michael. 1995. "Price-level Determinacy Without Control of a Monetary Aggregate." Carnegie-Rochester Conference Series on Public Policy, 43(1): 1-46.

[34] Woodford, Michael. 2003. Interest and Prices: Foundations of a Theory of Monetary Policy, Princeton, NJ: Princeton University Press. 


\section{Figures and Tables}
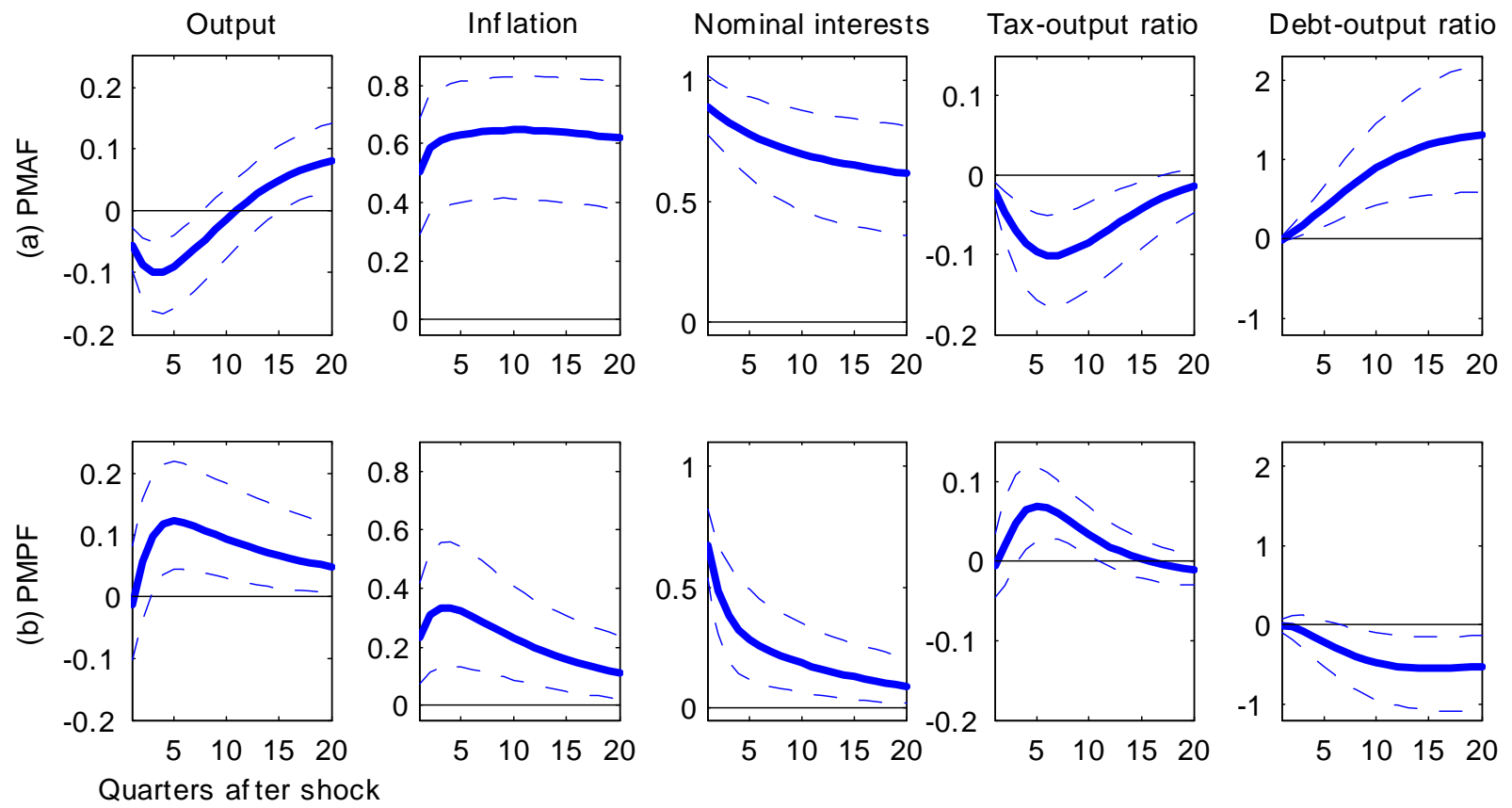

Figure 1: Impulse responses to monetary policy shocks in the pre-Volcker period

Note: Figure plots pointwise posterior means (solid lines) and 90-percent probability intervals (dashed lines) for impulse responses to a one standard deviation shock to $\varepsilon_{R, t}$. Row (a) presents results of the PMAF regime, pre-Volcker, and row (b) presents results of the PMPF regime, pre-Volcker. The unit of the impulse responses is percentage deviations from the steady state for output and percentage point deviations from the steady state for the rest of the variables. 

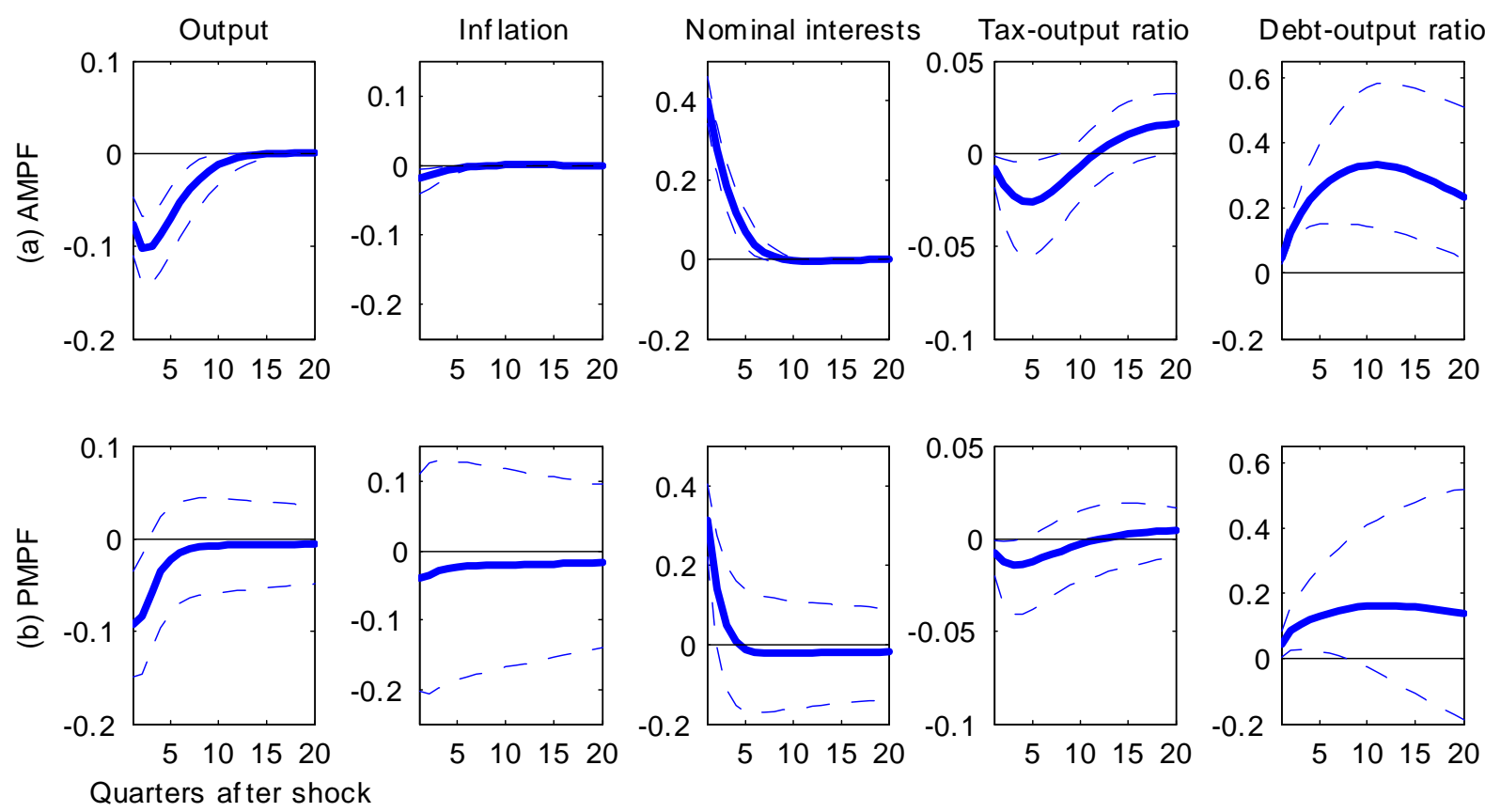

Figure 2: Impulse responses to monetary policy shocks in the post-Volcker period

Note: Figure plots pointwise posterior means (solid lines) and 90-percent probability intervals (dashed lines) for impulse responses to a one standard deviation shock to $\varepsilon_{R, t}$. Row (a) presents results of the AMPF regime, post-Volcker, and row (b) presents results of the PMPF regime, post-Volcker. The unit of the impulse responses is percentage deviations from the steady state for output and percentage point deviations from the steady state for the rest of the variables. 

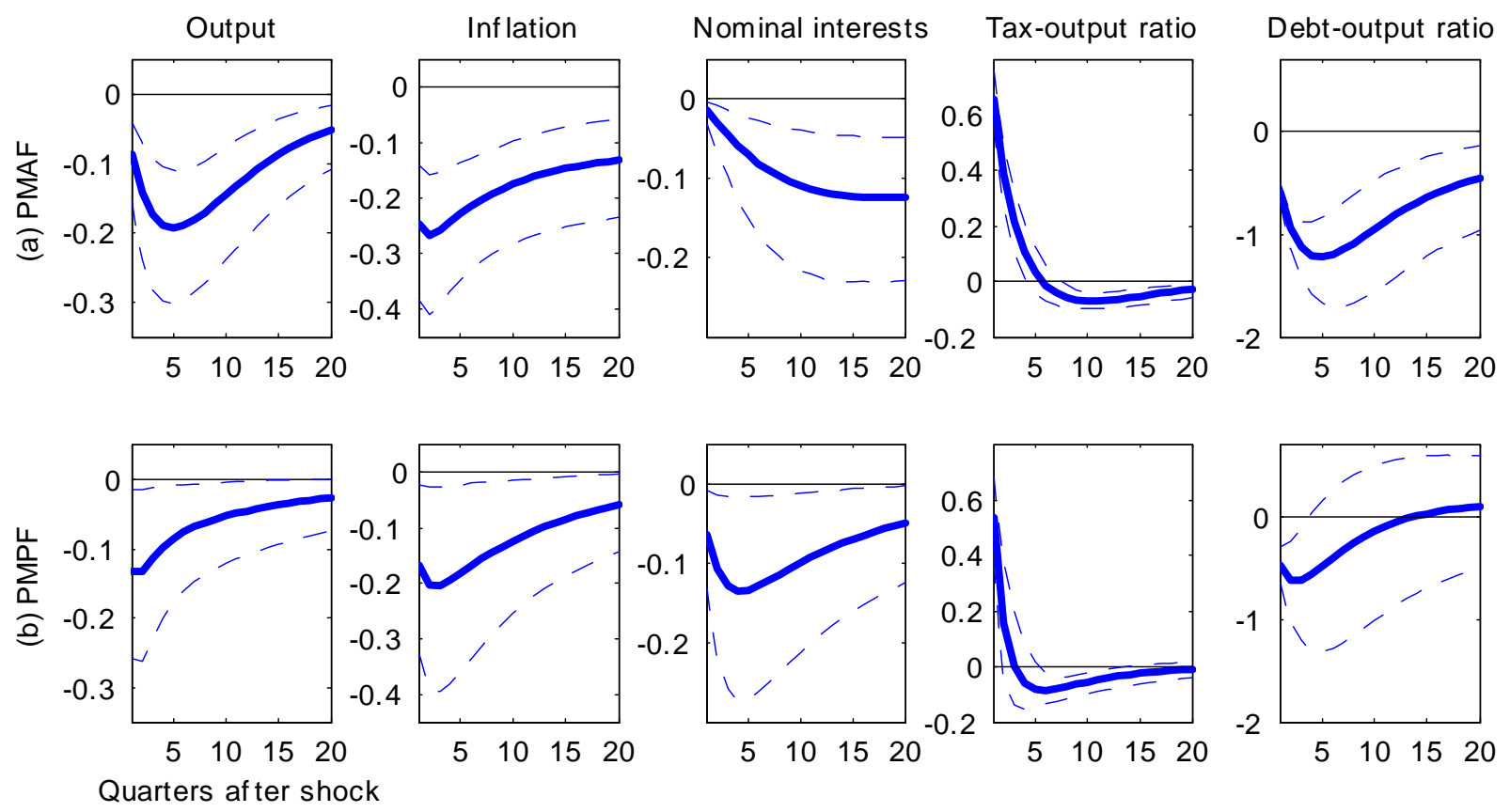

Figure 3: Impulse responses to fiscal policy shocks in the pre-Volcker period

Note: Figure plots pointwise posterior means (solid lines) and 90-percent probability intervals (dashed lines) for impulse responses to a one standard deviation shock to $\varepsilon_{\tau, t}$. Row (a) presents results of the PMAF regime, pre-Volcker, and row (b) presents results of the PMPF regime, pre-Volcker. The unit of the impulse responses is percentage deviations from the steady state for output and percentage point deviations from the steady state for the rest of the variables. 

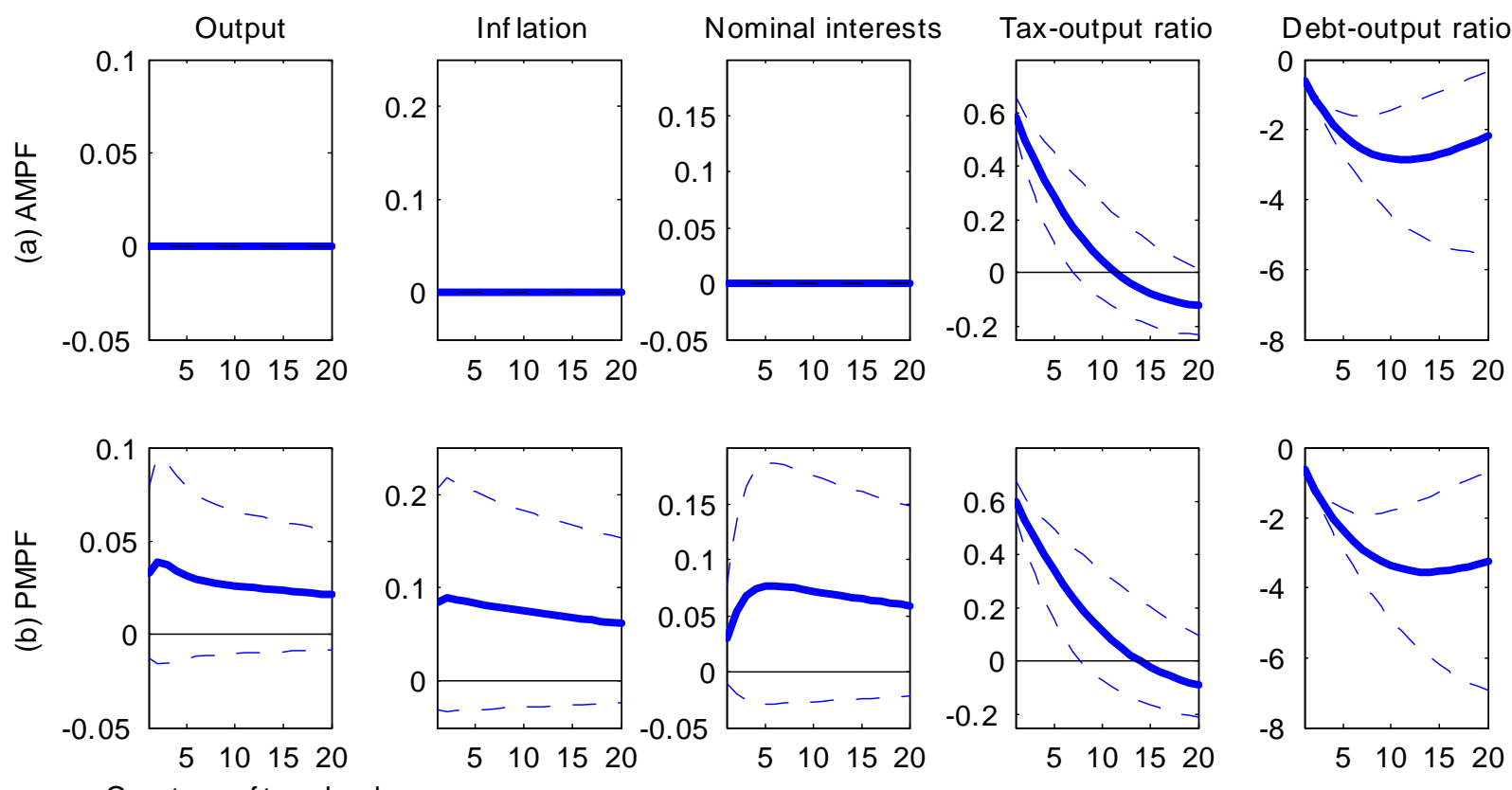

Figure 4: Impulse responses to fiscal policy shocks in the post-Volcker period

Note: Figure plots pointwise posterior means (solid lines) and 90-percent probability intervals (dashed lines) for impulse responses to a one standard deviation shock to $\varepsilon_{\tau, t}$. Row (a) presents results of the AMPF regime, post-Volcker, and row (b) presents results of the PMPF regime, post-Volcker. The unit of the impulse responses is percentage deviations from the steady state for output and percentage point deviations from the steady state for the rest of the variables. 

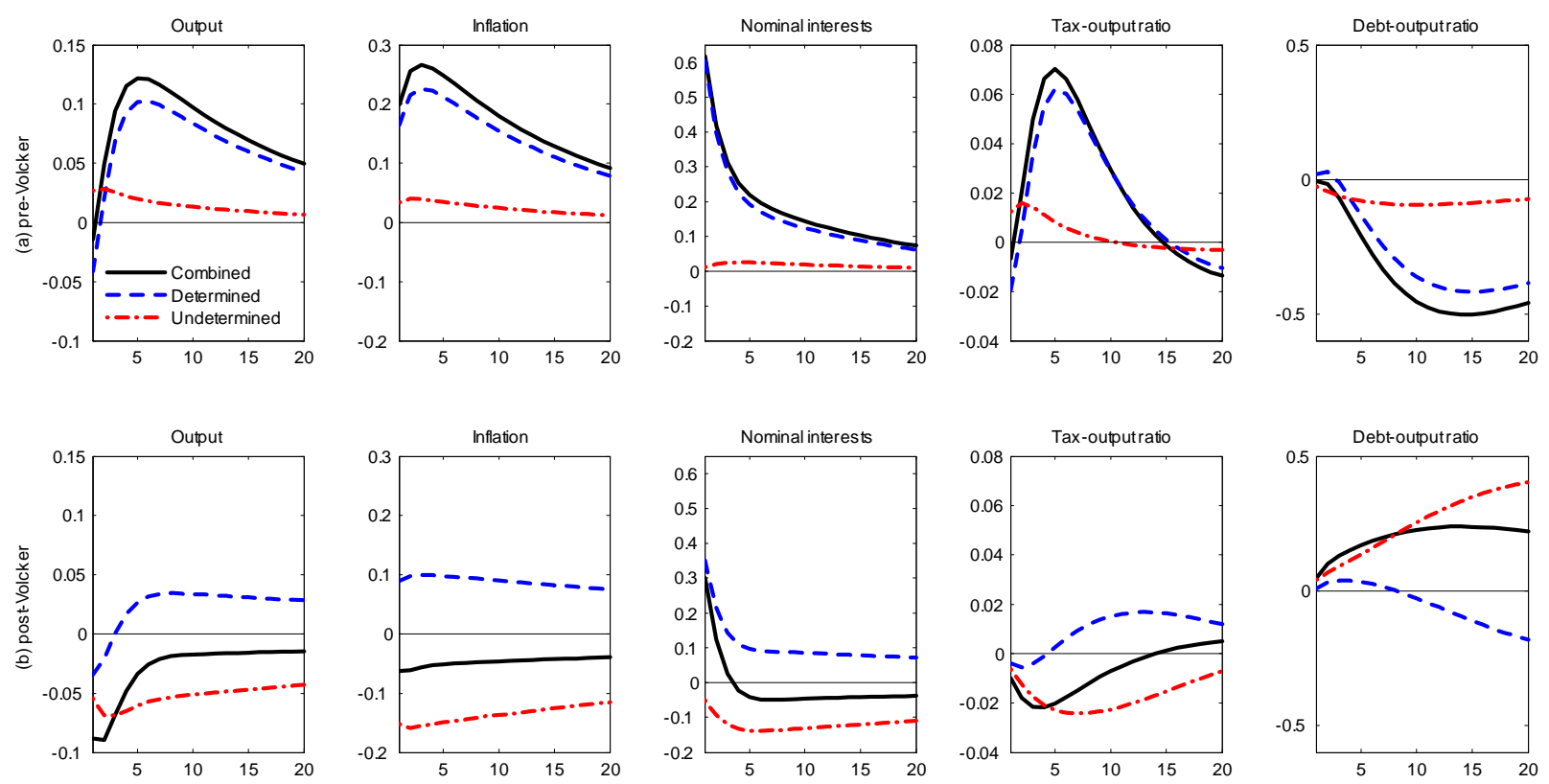

Figure 5: Decomposition of the impulse responses to monetary policy shocks

Note: Figure presents three impulse responses of each variable to one standard deviation shock to $\varepsilon_{R, t}$ : 1) impulse responses due to the determined part of initial impact of monetary policy shock, 2) impulse responses due to the undetermined part of initial impact of monetary policy shock, and 3) the combined impulse responses of 1) and 2). Row (a) presents the impulse responses under PMPF, pre-Volcker and row (b) presents the impulse responses under PMPF, post-Volcker. The impulse responses were computed at the posterior mode. 

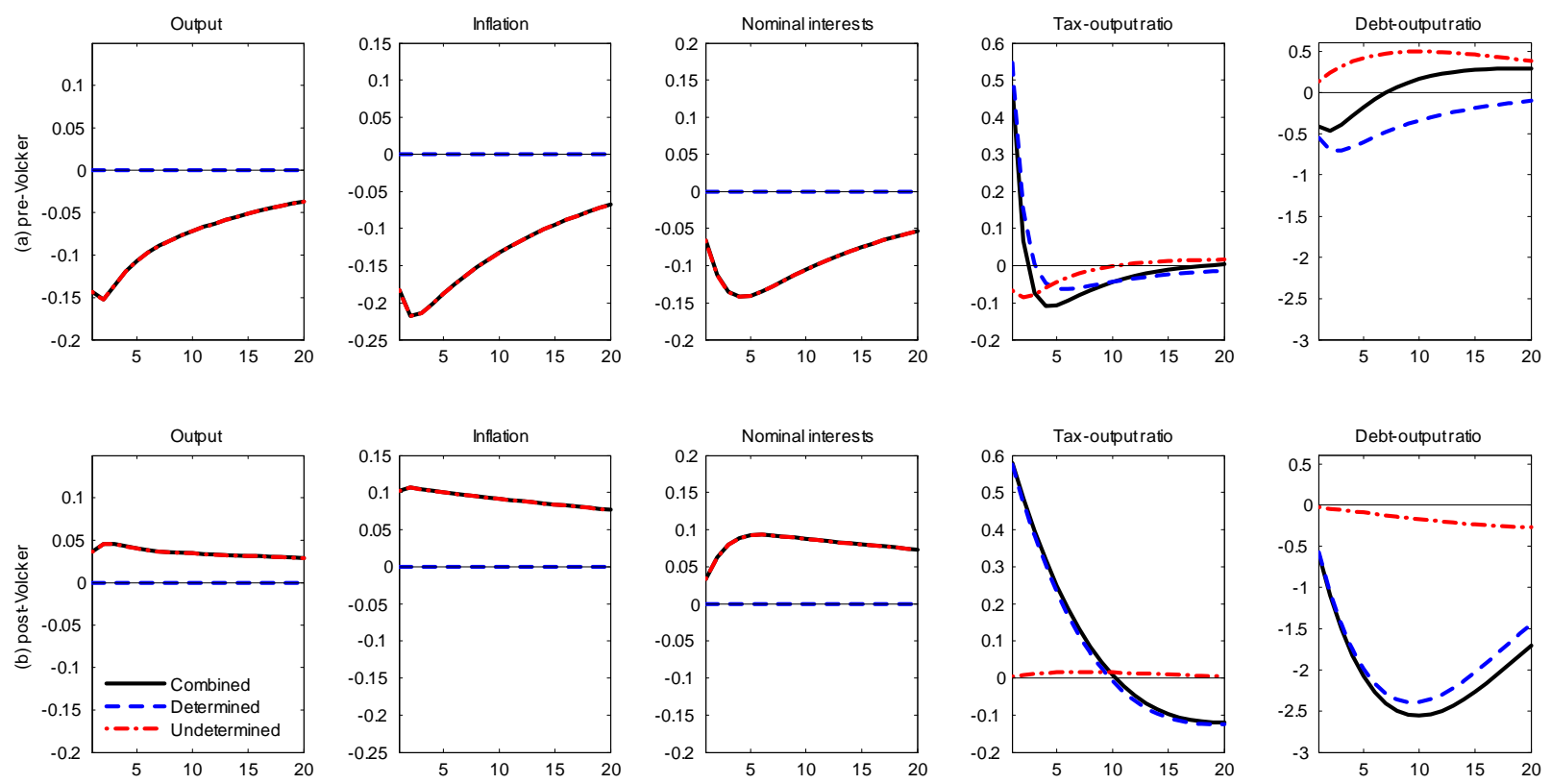

Figure 6: Decomposition of the impulse responses to fiscal policy shocks

Note: Figure presents three impulse responses of each variable to one standard deviation shock to $\varepsilon_{\tau, t}: 1$ ) impulse responses due to the determined part of initial impact of fiscal policy shock, 2) impulse responses due to the undetermined part of initial impact of fiscal policy shock, and 3) the combined impulse responses of 1) and 2). Row (a) presents the impulse responses under PMPF, pre-Volcker and row (b) presents the impulse responses under PMPF, post-Volcker. The impulse responses were computed at the posterior mode. 


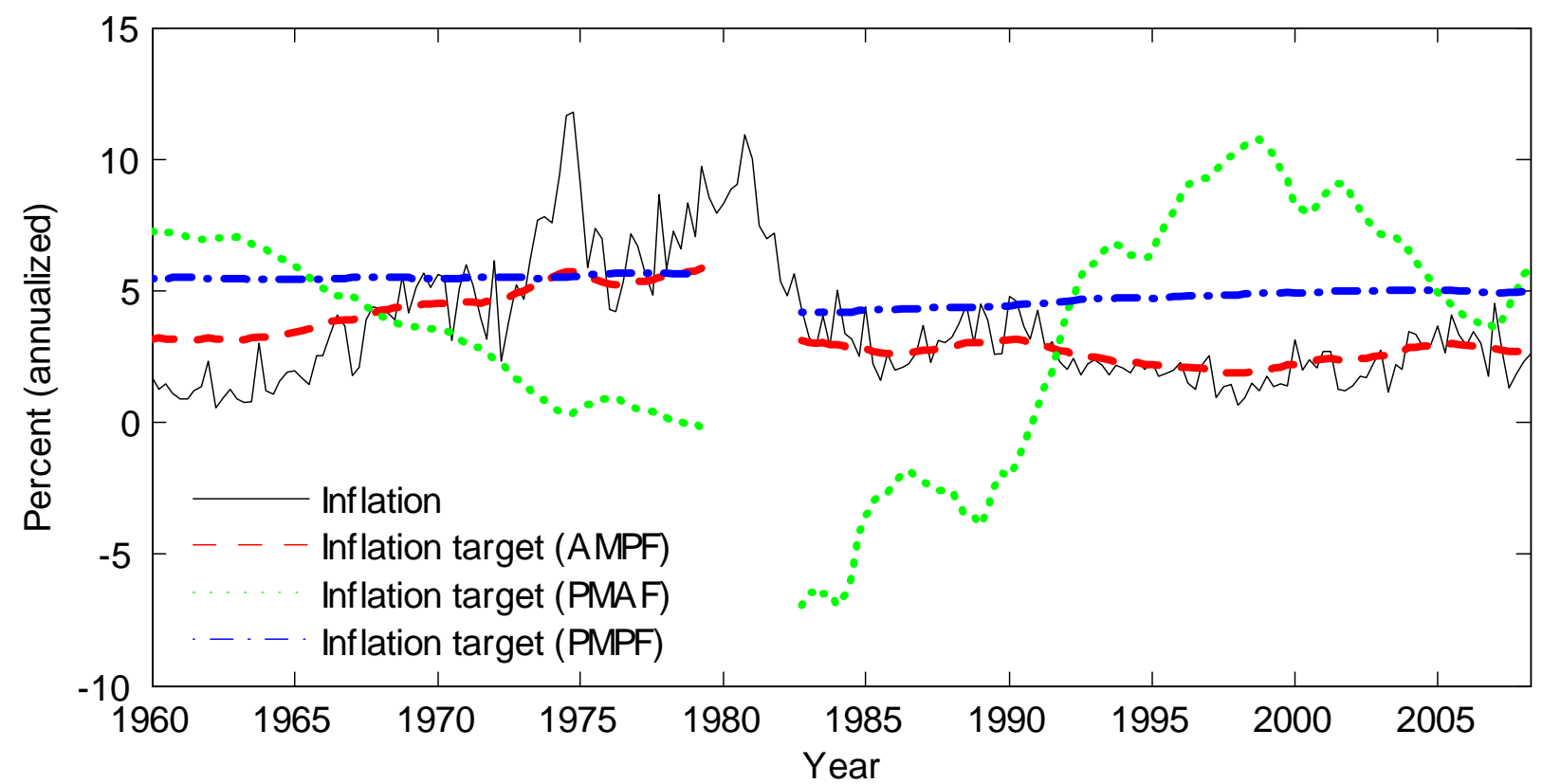

Figure 7: Smoothed inflation target and inflation

Note: Figure presents actual inflation and the point-wise mean of the smoothed values of the inflation target for the three policy regimes for both the pre- and the post-Volcker periods.

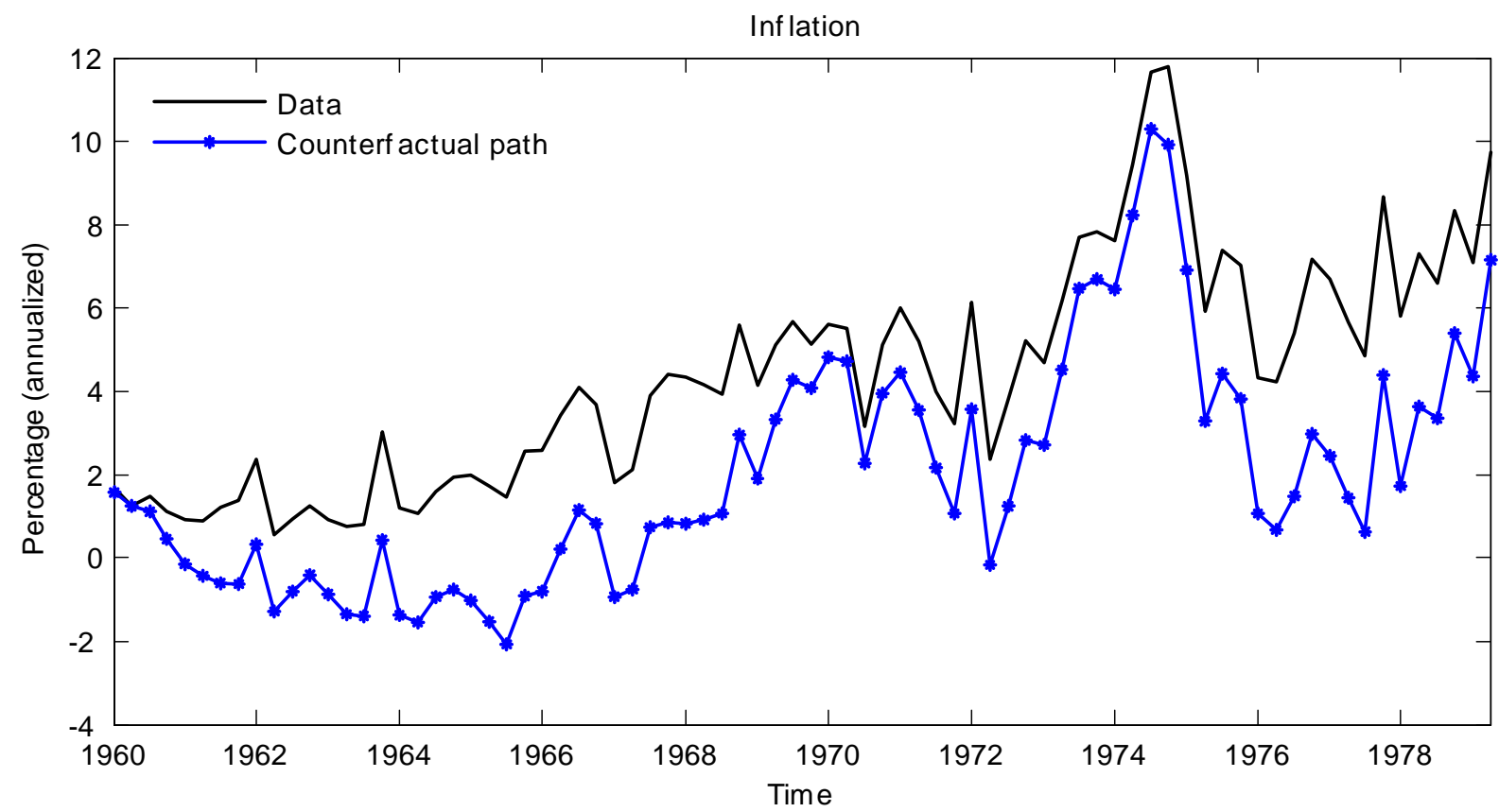

Figure 8: Counterfactual path of inflation with no preference shocks

Note: Figure presents actual and counterfactual path of inflation with the preference shock shut down in the pre-Volcker period under PMPF. The presented counterfactual paths are point-wise mean of counterfactual paths. 

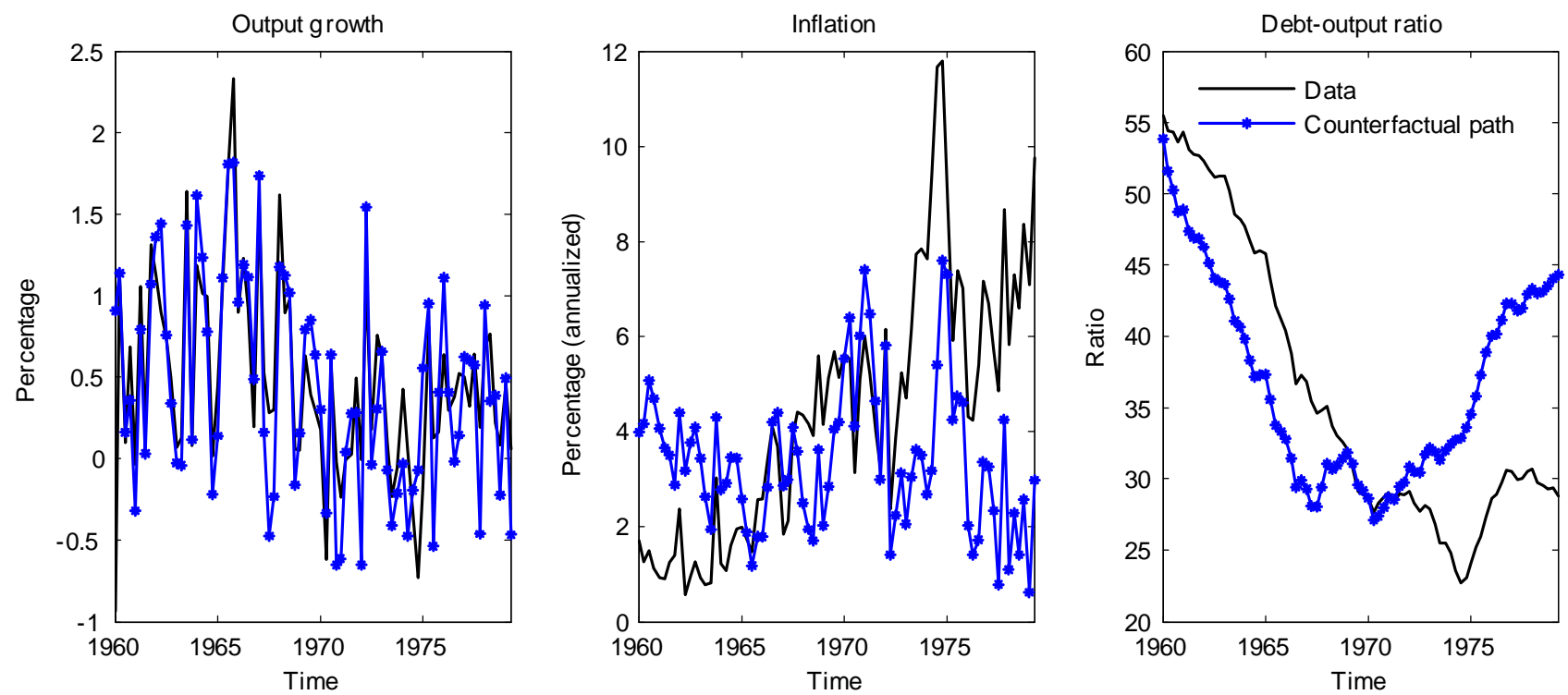

Figure 8: Counterfactual path of output growth, inflation, and debt-to-output ratio

Note: Figure presents actual and counterfactual path of the three variables. The distribution of counterfactual paths was first computed by changing the posterior draws of $\phi_{\pi}^{*}$ in the PMPF model pre-Volcker so that $\phi_{\pi}$ is set to 1.2991, the posterior mean of $\phi_{\pi}$ in the AMPF model post-Volcker. The presented counterfactual paths are point-wise mean of these counterfactual paths. The monetary policy shock and the inflation target shock were shut down. 
Table 1: Prior distribution of structural parameters

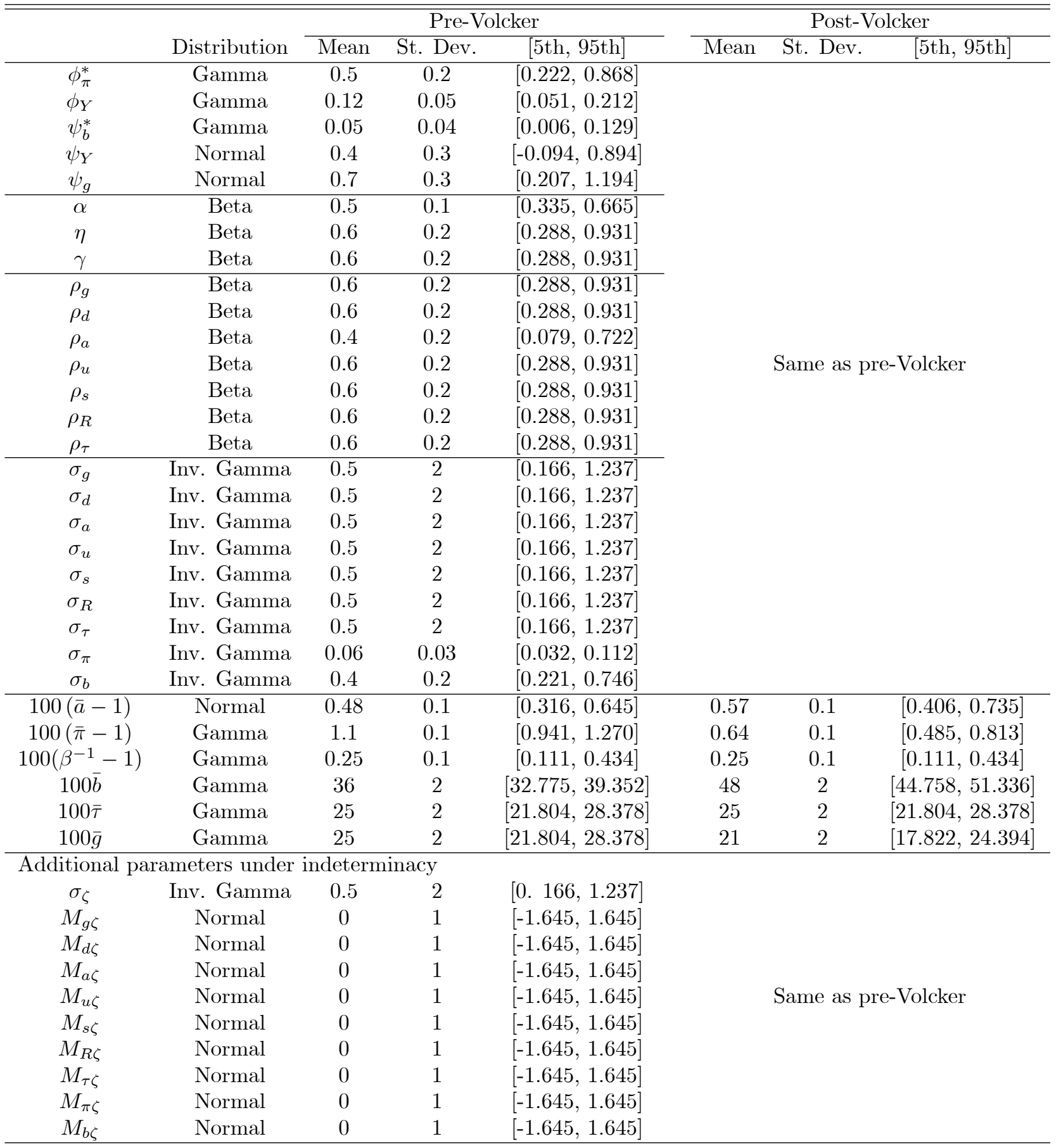

Note: The column labeled [5th, 9 th $]$ presents the 5 th and 95 th percentiles. The parameters $M_{g \zeta}, M_{d \zeta}, \cdots$, $M_{b \zeta}$ are entries of $M$ in (2). 
Table 2: Prior distribution of monetary and fiscal policy parameters

\begin{tabular}{ccccc}
\hline \hline Parameters & Policy & Mean & St. Dev. & {$[5$ th, 95th $]$} \\
\hline$\phi_{\pi}$ & Active Monetary & 1.500 & 0.200 & {$[1.189,1.811]$} \\
& Passive Monetary & 0.497 & 0.200 & {$[0.185,0.811]$} \\
$\psi_{b}$ & Active Fiscal & -0.047 & 0.040 & {$[-0.102,0.003]$} \\
& Passive Fiscal & 0.053 & 0.040 & {$[0.003,0.107]$} \\
\hline
\end{tabular}

Note: The last column presents the 5th and 95th percentiles. The prior distribution of $\phi_{\pi}$ and $\psi_{b}$ was obtained based on a simulation from the prior distribution of the structural parameters. Since the prior distribution of those parameters that determine the boundary condition of active and passive policy is identical pre-Volcker and post-Volcker, $\phi_{\pi}$ and $\psi_{b}$ also have the same prior distribution across the subsamples.

Table 3: Comparison of the marginal likelihood of alternate regimes

\begin{tabular}{cccc}
\hline \hline & \multicolumn{2}{c}{ Determinacy } & Indeterminacy \\
& AMPF & PMAF & PMPF \\
\hline Pre-Volcker & -542.0 & -539.8 & -522.1 \\
Post-Volcker & -554.4 & -564.5 & -569.8 \\
\hline
\end{tabular}

Note: Table reports log marginal likelihoods that are computed using the harmonic mean estimator proposed by John F. Geweke (1999). 
Table 4: Posterior distribution of structural parameters

\begin{tabular}{|c|c|c|c|c|}
\hline & \multicolumn{2}{|c|}{ Pre-Volcker (PMPF) } & \multicolumn{2}{|c|}{ Post-Volcker (AMPF) } \\
\hline & Mean & {$[5 \mathrm{th}, 95 \mathrm{th}]$} & Mean & {$[5 \mathrm{th}, 95 \mathrm{th}]$} \\
\hline$\phi_{\pi}^{*}$ & 0.799 & {$[0.631,0.986]$} & 0.454 & {$[0.170,0.719]$} \\
\hline$\phi_{\pi}$ & 0.188 & {$[0.000,0.354]$} & 1.299 & {$[0.922,1.680]$} \\
\hline$\phi_{Y}$ & 0.296 & {$[0.195,0.399]$} & 0.447 & {$[0.304,0.587]$} \\
\hline$\psi_{b}^{*}$ & 0.092 & {$[0.038,0.145]$} & 0.097 & {$[0.022,0.166]$} \\
\hline$\psi_{b}$ & 0.094 & {$[0.040,0.146]$} & 0.099 & {$[0.024,0.168]$} \\
\hline$\psi_{Y}$ & 0.748 & {$[0.512,0.984]$} & 0.738 & {$[0.317,1.163]$} \\
\hline$\psi_{g}$ & 0.448 & {$[0.120,0.772]$} & 0.232 & {$[-0.323,0.770]$} \\
\hline$\alpha$ & 0.696 & {$[0.580,0.818]$} & 0.838 & {$[0.775,0.899]$} \\
\hline$\eta$ & 0.217 & {$[0.062,0.367]$} & 0.722 & {$[0.597,0.861]$} \\
\hline$\gamma$ & 0.342 & {$[0.060,0.616]$} & 0.139 & {$[0.028,0.246]$} \\
\hline$\rho_{g}$ & 0.966 & {$[0.941,0.993]$} & 0.986 & {$[0.976,0.997]$} \\
\hline$\rho_{d}$ & 0.862 & {$[0.762,0.966]$} & 0.861 & {$[0.777,0.947]$} \\
\hline$\rho_{a}$ & 0.300 & {$[0.028,0.562]$} & 0.527 & {$[0.234,0.820]$} \\
\hline$\rho_{u}$ & 0.370 & {$[0.076,0.648]$} & 0.122 & {$[0.024,0.217]$} \\
\hline$\rho_{s}$ & 0.745 & {$[0.614,0.880]$} & 0.735 & {$[0.624,0.845]$} \\
\hline$\rho_{R}$ & 0.652 & {$[0.519,0.782]$} & 0.797 & {$[0.738,0.857]$} \\
\hline$\rho_{\tau}$ & 0.436 & {$[0.230,0.641]$} & 0.867 & {$[0.781,0.955]$} \\
\hline$\overline{\sigma_{g}}$ & 0.227 & {$[0.196,0.257]$} & 0.164 & {$[0.145,0.183]$} \\
\hline$\sigma_{d}$ & 0.278 & {$[0.176,0.379]$} & 0.489 & {$[0.199,0.803]$} \\
\hline$\sigma_{a}$ & 0.619 & {$[0.251,0.942]$} & 0.404 & {$[0.165,0.638]$} \\
\hline$\sigma_{u}$ & 0.200 & {$[0.150,0.250$} & 0.141 & {$[0.120,0.163]$} \\
\hline$\sigma_{s}$ & 1.018 & {$[0.880,1.151]$} & 1.361 & {$[1.201,1.516]$} \\
\hline$\sigma_{R}$ & 0.167 & {$[0.136,0.197]$} & 0.108 & {$[0.093,0.123]$} \\
\hline$\sigma_{\tau}$ & 0.597 & {$[0.481,0.716]$} & 0.582 & {$[0.507,0.656]$} \\
\hline$\sigma_{\pi}$ & 0.060 & {$[0.026,0.093]$} & 0.037 & {$[0.024,0.050]$} \\
\hline$\sigma_{b}$ & 0.348 & {$[0.170,0.525]$} & 0.400 & {$[0.173,0.618]$} \\
\hline $100(\bar{a}-1)$ & 0.401 & {$[0.302,0.502]$} & 0.589 & {$[0.488,0.690]$} \\
\hline $100(\bar{\pi}-1)$ & 1.052 & {$[0.897,1.202]$} & 0.644 & {$[0.481,0.801]$} \\
\hline $100\left(\beta^{-1}-1\right)$ & 0.160 & {$[0.057,0.258]$} & 0.236 & {$[0.099,0.371]$} \\
\hline $100 \bar{b}$ & 36.253 & {$[33.064,39.455]$} & 48.235 & {$[44.980,51.433]$} \\
\hline $100 \bar{\tau}$ & 25.051 & {$[24.119,25.970]$} & 24.524 & {$[23.534,25.516]$} \\
\hline $100 \bar{g}$ & 24.129 & {$[23.206,25.063]$} & 21.787 & {$[20.775,22.778]$} \\
\hline
\end{tabular}

Additional parameters under indeterminacy

$\begin{array}{lcc}\sigma_{\zeta} & 0.215 & {[0.129,0.298]} \\ M_{g \zeta} & 0.198 & {[-0.201,0.604]} \\ M_{d \zeta} & -0.391 & {[-1.124,0.341]} \\ M_{a \zeta} & 0.110 & {[-0.200,0.441]} \\ M_{u \zeta} & 0.358 & {[-0.191,0.903]} \\ M_{s \zeta} & -0.066 & {[-0.173,0.039]} \\ M_{R \zeta} & -0.219 & {[-0.826,0.380]} \\ M_{\tau \zeta} & 0.244 & {[0.016,0.475]} \\ M_{\pi \zeta} & 0.037 & {[-1.474,1.542]} \\ M_{b \zeta} & 0.010 & {[-0.659,0.680]}\end{array}$

Note: The column labeled [5th, 95th] presents the 5th and 95th percentiles. 
Table 5: Variance decompositions of inflation

\begin{tabular}{|c|c|c|c|c|}
\hline \multirow[b]{2}{*}{ Shocks } & \multicolumn{2}{|c|}{ Pre-Volcker (PMPF) } & \multicolumn{2}{|c|}{ Post-Volcker (AMPF) } \\
\hline & Short-Run (4 Q) & Long-Run (40 Q) & Short-Run (4 Q) & Long-Run (40 Q) \\
\hline Govt. spending & 0.006 & 0.002 & 0.000 & 0.000 \\
\hline$\varepsilon_{g, t}$ & {$[0.000,0.021]$} & {$[0.000,0.008]$} & {$[0.000,0.000]$} & {$[0.000,0.000]$} \\
\hline Preference & 0.187 & 0.422 & 0.052 & 0.016 \\
\hline$\varepsilon_{d, t}$ & {$[0.039,0.388]$} & {$[0.112,0.868]$} & {$[0.008,0.131]$} & {$[0.001,0.052]$} \\
\hline Technology & 0.410 & 0.177 & 0.000 & 0.000 \\
\hline$\varepsilon_{a, t}$ & {$[0.168,0.641]$} & {$[0.015,0.405]$} & {$[0.000,0.001]$} & {$[0.000,0.000]$} \\
\hline Mark-up & 0.184 & 0.247 & 0.726 & 0.173 \\
\hline$\varepsilon_{u, t}$ & {$[0.070,0.352]$} & {$[0.033,0.560]$} & {$[0.543,0.883]$} & {$[0.022,0.430]$} \\
\hline Transfer & 0.012 & 0.005 & 0.000 & 0.000 \\
\hline$\varepsilon_{s, t}$ & {$[0.000,0.040]$} & {$[0.000,0.020]$} & {$[0.000,0.000]$} & {$[0.000,0.000]$} \\
\hline Monetary policy & 0.081 & 0.046 & 0.001 & 0.000 \\
\hline$\varepsilon_{R, t}$ & {$[0.010,0.205]$} & {$[0.002,0.139]$} & {$[0.000,0.004]$} & {$[0.000,0.001]$} \\
\hline Tax revenues & 0.031 & 0.013 & 0.000 & 0.000 \\
\hline$\varepsilon_{\tau, t}$ & {$[0.001,0.088]$} & {$[0.000,0.045]$} & {$[0.000,0.000]$} & {$[0.000,0.000]$} \\
\hline Inflation target & 0.005 & 0.055 & 0.221 & 0.811 \\
\hline$\varepsilon_{\pi, t}$ & {$[0.000,0.023]$} & {$[0.000,0.245]$} & {$[0.094,0.379]$} & {$[0.545,0.973]$} \\
\hline Debt target & 0.019 & 0.008 & 0.000 & 0.000 \\
\hline$\varepsilon_{b, t}$ & {$[0.000,0.071]$} & {$[0.000,0.033]$} & {$[0.000,0.000]$} & {$[0.000,0.000]$} \\
\hline Sunspot & 0.066 & 0.027 & 0 & 0 \\
\hline$\varepsilon_{\zeta, t}$ & {$[0.0180,0.145]$} & {$[0.002,0.072]$} & - & - \\
\hline
\end{tabular}

Note: Means and [5th, 95th] posterior percentiles. 
Table 6: Variance decompositions of output growth

\begin{tabular}{|c|c|c|c|c|}
\hline \multirow[b]{2}{*}{ Shocks } & \multicolumn{2}{|c|}{ Pre-Volcker (PMPF) } & \multicolumn{2}{|c|}{ Post-Volcker (AMPF) } \\
\hline & Short-Run (4 Q) & Long-Run (40 Q) & Short-Run (4 Q) & Long-Run (40 Q) \\
\hline Govt. spending & 0.147 & 0.143 & 0.126 & 0.121 \\
\hline$\varepsilon_{g, t}$ & {$[0.0604,0.251]$} & {$[0.058,0.244]$} & {$[0.088,0.172]$} & {$[0.084,0.165]$} \\
\hline Preference & 0.165 & 0.165 & 0.573 & 0.575 \\
\hline$\varepsilon_{d, t}$ & {$[0.0176,0.352]$} & {$[0.0191,0.3505]$} & {$[0.411,0.715]$} & {$[0.413,0.715]$} \\
\hline Technology & 0.100 & 0.109 & 0.256 & 0.259 \\
\hline$\varepsilon_{a, t}$ & {$[0.0274,0.251]$} & {$[0.0351,0.254]$} & {$[0.120,0.423]$} & {$[0.126,0.426]$} \\
\hline Mark-up & 0.329 & 0.330 & 0.004 & 0.005 \\
\hline$\varepsilon_{u, t}$ & {$[0.1490,0.532]$} & {$[0.1516,0.5325]$} & {$[0.001,0.010]$} & {$[0.001,0.010]$} \\
\hline Transfer & 0.020 & 0.020 & 0.000 & 0.000 \\
\hline$\varepsilon_{s, t}$ & {$[0.000,0.066]$} & {$[0.000,0.0649]$} & {$[0.000,0.000]$} & {$[0.000,0.000]$} \\
\hline Monetary policy & 0.016 & 0.016 & 0.025 & 0.026 \\
\hline$\varepsilon_{R, t}$ & {$[0.005,0.042]$} & {$[0.005,0.042]$} & {$[0.009,0.050]$} & {$[0.010,0.050]$} \\
\hline Tax revenues & 0.062 & 0.060 & 0.000 & 0.000 \\
\hline$\varepsilon_{\tau, t}$ & {$[0.002,0.170]$} & {$[0.002,0.166]$} & {$[0.000,0.000]$} & {$[0.000,0.000]$} \\
\hline Inflation target & 0.007 & 0.007 & 0.016 & 0.015 \\
\hline$\varepsilon_{\pi, t}$ & {$[0.000,0.031]$} & {$[0.000,0.030]$} & {$[0.006,0.032]$} & {$[0.005,0.031]$} \\
\hline Debt target & 0.036 & 0.035 & 0.000 & 0.000 \\
\hline$\varepsilon_{b, t}$ & {$[0.000,0.132]$} & {$[0.000,0.129]$} & {$[0.000,0.000]$} & {$[0.000,0.000]$} \\
\hline Sunspot & 0.117 & 0.114 & 0 & 0 \\
\hline$\varepsilon_{\zeta, t}$ & {$[0.041,0.235]$} & {$[0.041,0.230]$} & - & - \\
\hline
\end{tabular}

Note: Means and [5th, 95th] posterior percentiles. 
Table 7: Variance decompositions of debt-to-output ratio

\begin{tabular}{|c|c|c|c|c|}
\hline \multirow[b]{2}{*}{ Shocks } & \multicolumn{2}{|c|}{ Pre-Volcker (PMPF) } & \multicolumn{2}{|c|}{ Post-Volcker (AMPF) } \\
\hline & Short-Run (4 Q) & Long-Run (40 Q) & Short-Run (4 Q) & Long-Run (40 Q) \\
\hline Govt. spending & 0.016 & 0.214 & 0.017 & 0.416 \\
\hline$\varepsilon_{g, t}$ & {$[0.000,0.045]$} & {$[0.006,0.614]$} & {$[0.010,0.027]$} & {$[0.006,0.874]$} \\
\hline Preference & 0.014 & 0.197 & 0.025 & 0.042 \\
\hline$\varepsilon_{d, t}$ & {$[0.000,0.052]$} & {$[0.030,0.450]$} & {$[0.002,0.075]$} & {$[0.000,0.185]$} \\
\hline Technology & 0.129 & 0.160 & 0.006 & 0.002 \\
\hline$\varepsilon_{a, t}$ & {$[0.010,0.301]$} & {$[0.014,0.388]$} & {$[0.002,0.013]$} & {$[0.000,0.007]$} \\
\hline Mark-up & 0.126 & 0.210 & 0.000 & 0.001 \\
\hline$\varepsilon_{u, t}$ & {$[0.041,0.244]$} & {$[0.041,0.465]$} & {$[0.000,0.000]$} & {$[0.000,0.002]$} \\
\hline Transfer & 0.608 & 0.047 & 0.736 & 0.177 \\
\hline$\varepsilon_{s, t}$ & {$[0.418,0.768]$} & {$[0.000,0.239]$} & {$[0.636,0.825]$} & {$[0.001,0.611]$} \\
\hline Monetary policy & 0.005 & 0.035 & 0.003 & 0.002 \\
\hline$\varepsilon_{R, t}$ & {$[0.000,0.021]$} & {$[0.001,0.112]$} & {$[0.001,0.007]$} & {$[0.000,0.006]$} \\
\hline Tax revenues & 0.0565 & 0.011 & 0.210 & 0.170 \\
\hline$\varepsilon_{\tau, t}$ & {$[0.002,0.183]$} & {$[0.000,0.041]$} & {$[0.112,0.316]$} & {$[0.000,0.690]$} \\
\hline Inflation target & 0.002 & 0.002 & 0.002 & 0.103 \\
\hline$\varepsilon_{\pi, t}$ & {$[0.000,0.009]$} & {$[0.000,0.007]$} & {$[0.001,0.006]$} & {$[0.003,0.323]$} \\
\hline Debt target & 0.011 & 0.098 & 0.000 & 0.090 \\
\hline$\varepsilon_{b, t}$ & {$[0.000,0.041]$} & {$[0.001,0.360]$} & {$[0.000,0.000]$} & {$[0.002,0.306]$} \\
\hline Sunspot & 0.033 & 0.026 & 0 & 0 \\
\hline$\varepsilon_{\zeta, t}$ & {$[0.008,0.078]$} & {$[0.002,0.071]$} & - & - \\
\hline
\end{tabular}

Note: Means and [5th, 95th] posterior percentiles. 


\section{Appendix}

\section{A System of equilibrium conditions}

The technology process $A_{t}$ induces a common trend in output $Y_{t}$, consumption $C_{t}$, real wage $\frac{\tilde{W}_{t}(i)}{P_{t}}$, government purchases $G_{t}$, government debt $B_{t} / P_{t}$, tax revenues $T_{t}$, and transfers $S_{t}$. Since we solve the model through a local approximation of its dynamics around a steady state, we first detrend the variables as

$$
\tilde{Y}_{t} \equiv \frac{Y_{t}}{A_{t}}, \tilde{C}_{t} \equiv \frac{C_{t}}{A_{t}}, \text { and } \frac{\tilde{W}_{t}(i)}{P_{t}} \equiv \frac{W_{t}(i)}{P_{t} A_{t}} .
$$

Note that the fiscal variables, $b_{t}=B_{t} / P_{t} Y_{t}, g_{t}=G_{t} / Y_{t}, \tau_{t}=T_{t} / Y_{t}$, and $s_{t}=S_{t} / Y_{t}$ are already stationary. We then rewrite the equilibrium conditions in terms of the detrended variables, compute the non-stochastic steady state, and then take a first-order approximation around the steady state. In the ensuing subsections, we present the equilibrium conditions in terms of the detrended variables and their first order approximations.

\section{A.1 Equilibrium conditions in terms of detrended variables}

- Consumption Euler equation:

$$
\beta E_{t}\left[\frac{1}{\pi_{t+1}} \frac{\left(\tilde{C}_{t}-\eta \tilde{C}_{t-1} a_{t}^{-1}\right)}{\left(\tilde{C}_{t+1}-\eta \tilde{C}_{t} a_{t+1}^{-1}\right)} \frac{\delta_{t+1}}{\delta_{t}} \frac{1}{a_{t+1}}\right]=\frac{1}{R_{t}}
$$

- Labor supply:

$$
\left(H_{t}^{j}\right)^{\varphi}\left(\tilde{C}_{t}-\eta \tilde{C}_{t-1} a_{t}^{-1}\right)=\frac{\tilde{W}_{t}(j)}{P_{t}}
$$

- Production function:

$$
\tilde{Y}_{t}(i)=H_{t}(i)
$$

- Demand function:

$$
\tilde{Y}_{t}(i)=\left[\tilde{p}_{t}(i)\right]^{-\theta_{t}} \tilde{Y}_{t}, \quad \text { where } \tilde{p}_{t}(i)=\frac{P_{t}(i)}{P_{t}}
$$


- Firms' optimality condition:

$$
E_{t} \sum_{k=0}^{\infty}(\alpha \beta)^{k} \frac{\left(\tilde{C}_{t}-\eta \tilde{C}_{t-1} a_{t}^{-1}\right) \delta_{t+k}}{\left(\tilde{C}_{t+k}-\eta \tilde{C}_{t+k-1} a_{t+k}^{-1}\right) \delta_{t}} \tilde{Y}_{t+k}(i)\left[\frac{\tilde{p}_{t}(i) X_{t, k}}{\prod_{s=1}^{k} \pi_{t+s}}-\left(\frac{\theta_{t}}{\theta_{t}-1}\right) \frac{\tilde{W}_{t+k}(j)}{P_{t+k}}\right]=0
$$

- Dixit-Stiglitz price aggregator:

$$
1=\left[(1-\alpha) \tilde{p}_{t}^{* 1-\theta_{t}}+\alpha\left\{\frac{\bar{\pi}}{\pi_{t}}\left(\frac{\pi_{t-1}}{\bar{\pi}}\right)^{\gamma}\right\}^{1-\theta_{t}}\right]^{\frac{1}{1-\theta_{t}}} .
$$

- Government budget constraint:

$$
b_{t}=R_{t-1} b_{t-1} \frac{1}{\pi_{t}} \frac{\tilde{Y}_{t-1}}{\tilde{Y}_{t}} \frac{1}{a_{t}}+g_{t}-\tau_{t}+s_{t}
$$

- Monetary policy rule:

$$
\frac{R_{t}}{\bar{R}}=\left(\frac{R_{t-1}}{\bar{R}}\right)^{\rho_{r}}\left[\left(\frac{\pi_{t}}{\pi_{t}^{*}}\right)^{\phi_{\pi}}\left(\frac{\tilde{Y}_{t}}{\tilde{Y}_{t}^{*}}\right)^{\phi_{Y}}\right]^{1-\rho_{r}} e^{\varepsilon_{r, t}} .
$$

- Fiscal policy rule:

$$
\frac{\tau_{t}}{\bar{\tau}}=\left(\frac{\tau_{t-1}}{\bar{\tau}}\right)^{\rho_{\tau}}\left[\left(\frac{b_{t-1}}{b_{t-1}^{*}}\right)^{\tilde{\psi}_{b}}\left(\frac{\tilde{Y}_{t}}{\tilde{Y}_{t}^{*}}\right)^{\tilde{\psi}_{Y}}\left(\frac{g_{t}}{\bar{g}}\right)^{\tilde{\psi}_{g}}\right]^{1-\rho_{\tau}} e^{\tilde{\varepsilon}_{\tau, t}}
$$

- Resource constraint:

$$
\tilde{Y}_{t}=\tilde{C}_{t}+g_{t} \tilde{Y}_{t}
$$

\section{A.2 First order approximation}

We here present first-order approximation of the equations that are necessary to determine equilibrium dynamics of the observables.

- Consumption Euler equation:

$$
\widehat{\tilde{C}}_{t}=\frac{a}{a+\eta} E_{t} \widehat{\widetilde{C}}_{t+1}+\frac{\eta}{a+\eta} \widehat{\widetilde{C}}_{t-1}-\frac{a-\eta}{a+\eta}\left(\hat{R}_{t}-E_{t} \hat{\pi}_{t+1}\right)+\frac{a}{a+\eta} E_{t} \hat{a}_{t+1}-\frac{\eta}{a+\eta} \hat{a}_{t}+\frac{a-\eta}{a+\eta} \hat{d}_{t},
$$

where $\hat{d}_{t} \equiv\left(1-\rho_{\delta}\right) \hat{\delta}_{t}$. 
- NK Phillips curve:

$$
\begin{aligned}
\hat{\pi}_{t} & =\frac{\beta}{1+\gamma \beta} E_{t} \hat{\pi}_{t+1}+\frac{\gamma}{1+\gamma \beta} \hat{\pi}_{t-1} \\
& +\frac{(1-\alpha \beta)(1-\alpha)}{\alpha(1+\varphi \theta)(1+\gamma \beta)}\left[\left(\varphi+\frac{a}{a-\eta}\right)\left(\widehat{\tilde{Y}}_{t}-\widehat{\tilde{Y}}_{t}^{*}\right)-\frac{\eta}{a-\eta}\left(\widehat{\tilde{Y}}_{t-1}-\widehat{\tilde{Y}}_{t-1}^{*}\right)\right]+\widehat{u}_{t},
\end{aligned}
$$

where $\hat{u}_{t} \equiv-\frac{(1-\alpha \beta)(1-\alpha)}{\alpha(1+\varphi \theta)(1+\gamma \beta)} \frac{1}{\theta-1} \hat{\theta}_{t}$ can be interpreted as cost-push shocks.

- Monetary policy rule:

$$
\hat{R}_{t}=\rho_{R} \hat{R}_{t-1}+\left(1-\rho_{R}\right)\left[\phi_{\pi}\left(\hat{\pi}_{t}-\hat{\pi}_{t}^{*}\right)+\phi_{Y}\left(\widehat{\tilde{Y}}_{t}-\widehat{\tilde{Y}}_{t}^{*}\right)\right]+\varepsilon_{R, t} .
$$

- Fiscal policy rule:

$$
\hat{\tau}_{t}=\rho_{\tau} \hat{\tau}_{t-1}+\left(1-\rho_{\tau}\right)\left[\psi_{b}\left(\hat{b}_{t-1}-\hat{b}_{t-1}^{*}\right)+\psi_{Y}\left(\hat{\tilde{Y}}_{t}-\widehat{\tilde{Y}}_{t}^{*}\right)+\psi_{g} \hat{g}_{t}\right]+\varepsilon_{\tau, t}
$$

where $\psi_{b}, \psi_{Y}$ and $\psi_{g}$ are respectively scaled counterparts of $\tilde{\psi}_{b}, \tilde{\psi}_{Y}$ and $\tilde{\psi}_{g}$ :

$$
\psi_{b} \equiv \frac{\bar{\tau}}{\bar{b}} \tilde{\psi}_{b}, \quad \psi_{Y} \equiv \bar{\tau} \tilde{\psi}_{Y}, \quad \psi_{g} \equiv \frac{\bar{\tau}}{\bar{g}} \tilde{\psi}_{g}
$$

and $\varepsilon_{\tau, t}$ is given as:

$$
\varepsilon_{\tau, t} \equiv \bar{\tau} \tilde{\varepsilon}_{\tau, t} \sim \text { i.i.d. } N\left(0, \sigma_{\tau}^{2}\right)
$$

- Government budget constraint:

$$
\hat{b}_{t}=\beta^{-1} \hat{b}_{t-1}+\beta^{-1} b\left(\hat{R}_{t-1}-\hat{\pi}_{t}-\widehat{\tilde{Y}}_{t}+\widehat{\tilde{Y}}_{t-1}-\hat{a}_{t}\right)+\hat{g}_{t}-\hat{\tau}_{t}+\hat{s}_{t}
$$

- Resource constraint:

$$
\widehat{\tilde{Y}}_{t}=\widehat{\tilde{C}}_{t}+\frac{1}{1-g} \hat{g}_{t}
$$

- Natural level of output:

$$
\begin{aligned}
\widehat{\tilde{Y}}_{t}^{*} & =\frac{\eta}{\varphi(a-\eta)+a} \widehat{\tilde{Y}}_{t-1}^{*}+\frac{a}{[\varphi(a-\eta)+a](1-g)} \hat{g}_{t}-\frac{\eta}{[\varphi(a-\eta)+a](1-g)} \hat{g}_{t-1} \\
& -\frac{\eta}{\varphi(a-\eta)+a} \hat{a}_{t} .
\end{aligned}
$$


- $\mathrm{AR}(1)$ processes for exogenous shocks:

$$
\begin{aligned}
& \hat{g}_{t}=\rho_{g} \hat{g}_{t-1}+\varepsilon_{g, t}, \\
& \hat{d}_{t}=\rho_{d} \hat{d}_{t-1}+\varepsilon_{d, t}, \\
& \hat{a}_{t}=\rho_{a} \hat{a}_{t-1}+\varepsilon_{a, t}, \\
& \widehat{u}_{t}=\rho_{u} \widehat{u}_{t-1}+\varepsilon_{u, t}, \\
& \widehat{s}_{t}=\rho_{s} \widehat{s}_{t-1}+\varepsilon_{s, t}, \\
& \hat{\pi}_{t}^{*}=\rho_{\pi} \hat{\pi}_{t-1}^{*}+\varepsilon_{\pi, t}, \\
& \hat{b}_{t}^{*}=\rho_{b} \hat{b}_{t-1}^{*}+\varepsilon_{b, t} .
\end{aligned}
$$




\section{B Data description}

We use the following definitions for our data variables: per capita output $=$ (personal consumption of nondurable+personal consumption of services+government consumption) / civilian noninstitutional population; annualized inflation $=400 \times \Delta \log (\mathrm{GDP}$ deflator $)$; annualized interest rates $=$ the quarterly average of daily effective federal funds rates; tax revenues $=$ current tax receipts + contributions for government social insurance; government debt $=$ market value of privately held gross federal debt; and government purchases = government consumption. Note that we use a single price level, GDP deflator, for all the model variables (e.g. output, government debt, tax revenues, and government purchases).

The effective federal funds rate and civilian noninstitutional population data were obtained from the FRED database of Federal Reserve Bank of St. Louis. The market value of privately held gross federal debt series was obtained from Federal Reserve Bank of Dallas. All the other data were taken from National Income and Product Accounts (NIPA) tables.

\section{Solution method under indeterminacy}

This section describes the solution method of a linear rational expectations (LRE) model under indeterminacy proposed by Lubik and Schorfheide (2004). Then we discuss an identification problem in their method and how to address the problem.

\section{C.1 Sims (2002)}

Lubik and Schorfheide (2004) starts with the following canonical form of LRE models by Sims (2002)

$$
\Gamma_{0} \mathbf{z}_{t}=\Gamma_{1} \mathbf{z}_{t-1}+\Psi \varepsilon_{t}+\Pi \boldsymbol{\eta}_{t}
$$

where $\mathbf{z}_{t}$ is an $n \times 1$ vector of model variables, $\varepsilon_{t}$ is an $l \times 1$ vector of fundamental shocks, and $\boldsymbol{\eta}_{t}$ is a $k \times 1$ vector of expectational errors, satisfying $E_{t} \boldsymbol{\eta}_{t+1}=0$. We consider a case in which the exogenous fundamental shock process $\varepsilon_{t}$ is serially uncorrelated. ${ }^{26}$ Using the QZ (generalized Schur) decomposition, the coefficient matrices $\Gamma_{0}$ and $\Gamma_{1}$ can be decomposed as $\Gamma_{0}=Q^{\prime} \Lambda Z^{\prime}, \Gamma_{1}=Q^{\prime} \Omega Z^{\prime}$ where $\Lambda$ and $\Omega$ are upper triangular and $Q$ and $Z$ are unitary: $Q Q^{\prime}=Q^{\prime} Q=I$ and $Z Z^{\prime}=Z^{\prime} Z=I$. Let $\mathbf{w}_{t}=Z^{\prime} \mathbf{z}_{t}$ and multiply both sides of Equation (3)

\footnotetext{
${ }^{26} \mathrm{~A}$ model with a serially correlated shock process can always be rewritten so that the model has a serially uncorrelated shock process by augmenting $y_{t}$ to include the original shock process.
} 
by $Q$ to obtain

$$
\left[\begin{array}{cc}
\Lambda_{11} & \Lambda_{12} \\
0 & \Lambda_{22}
\end{array}\right]\left[\begin{array}{l}
\mathbf{w}_{1, t} \\
\mathbf{w}_{2, t}
\end{array}\right]=\left[\begin{array}{cc}
\Omega_{11} & \Omega_{12} \\
0 & \Omega_{22}
\end{array}\right]\left[\begin{array}{l}
\mathbf{w}_{1, t-1} \\
\mathbf{w}_{2, t-1}
\end{array}\right]+\left[\begin{array}{c}
Q_{1} . \\
Q_{2} .
\end{array}\right]\left(\Psi \varepsilon_{t}+\Pi \boldsymbol{\eta}_{t}\right),
$$

where the generalized eigenvalues of the QZ decomposition (the ratios of diagonal elements of $\Omega$ and $\Lambda$ ) are ordered such that explosive eigenvalues (ones that do not meet the growth condition for $\mathbf{z}_{t}$ ) are in the lower right corner and $\Lambda, \Omega$ and $Q$ are partitioned accordingly.

Now suppose that there are $m$ unstable generalized eigenvalues $(m \leq n)$. That is, $Q_{2}$. is an $m \times n$ matrix. When the explosive components (decoupled from the first stable components) are solved forward, it is a function of the current and future values of $\boldsymbol{\varepsilon}_{t}$ and $\boldsymbol{\eta}_{t}$. For a stable solution to Equation (3) to exist, this forward solution of the unstable part should be constant and therefore it should hold that

$$
Q_{2 \cdot}\left(\Psi \varepsilon_{t}+\Pi \boldsymbol{\eta}_{t}\right)=0
$$

Since $\varepsilon_{t}$ is exogenous, we need $\boldsymbol{\eta}_{t}$ to be determined so that the condition (4) is satisfied (for every possible path of $\varepsilon_{t}$ ). The condition (4) is satisfied when the column space spanned by $Q_{2} . \Psi$ be contained by the column space spanned by $Q_{2} . \Pi$.

\section{C.2 Lubik and Schorfheide (2004)}

A necessary and sufficient condition that a solution to (3) be unique is that the row space spanned by $Q_{1} . \Pi$ be contained by the row space spanned by $Q_{2} . \Pi$. Then, the expectational error for the stable part is expressed as a function of the fundamental shock. The condition is met when there exists a conformable matrix $\Phi$ such that

$$
Q_{1} \cdot \Pi=\Phi Q_{2} \cdot \Pi
$$

When the condition (4) is satisfied but (5) is not, $\eta_{t}$ is not completely pinned down by $\varepsilon_{t}$.

There always exists a singular value decomposition (SVD) of $Q_{2}$. $I$ as

$$
\underbrace{Q_{2} . \Pi}_{m \times k}=\left[\begin{array}{ll}
\underbrace{U_{\cdot 1}}_{m \times r} & \underbrace{U_{\cdot 2}}_{m \times(k-r)}
\end{array}\right]\left[\begin{array}{cc}
\underbrace{D_{11}}_{r \times r} & 0 \\
0 & 0
\end{array}\right]\left[\begin{array}{c}
\underbrace{V_{\cdot 1}^{\prime}}_{r \times k} \\
\underbrace{V_{\cdot 2}^{\prime}}_{(k-r) \times k}
\end{array}\right],
$$

where $D_{11}$ is a diagonal matrix with nonzero singular values on its diagonal and $U=\left[\begin{array}{ll}U_{\cdot 1} & U_{\cdot 2}\end{array}\right]$ 
and $V=\left[\begin{array}{ll}V_{\cdot 1} & V_{\cdot 2}\end{array}\right]$ are unitary. Suppose that there are $r \leq m$ nonzero singular values. Then the $m$ explosive components of $\mathbf{z}_{t}$ generate only $r$ restrictions for $\boldsymbol{\eta}_{t}$. When $r=m$, we have enough restrictions to pin down the expectations of the model and there exists a unique solution. Otherwise, there exist multiple equilibria.

Lubik and Schorfheide (2004) introduce sunspot shocks and assume that the undetermined dimensions of $\boldsymbol{\eta}_{t}$ are affected by the sunspot shocks additively. Let

$$
\boldsymbol{\eta}_{t}=A_{1} \varepsilon_{t}+A_{2} \boldsymbol{\zeta}_{t}^{*}
$$

where $\boldsymbol{\zeta}_{t}^{*}$ is a $p \times 1$ vector of sunspot shocks with $E_{t} \boldsymbol{\zeta}_{t+1}^{*}=0, A_{1}$ is a $k \times l$ matrix and $A_{2}$ is a $k \times p$ matrix. Then $A_{1}$ and $A_{2}$ characterize the full set of solutions to the model (3). Lubik and Schorfheide (2004) show that the full set of solutions are given as

$$
\boldsymbol{\eta}_{t}=\left(-V_{\cdot 1} D_{11}^{-1} U_{\cdot 1}^{\prime} Q_{2 \cdot} \Psi+V_{\cdot 2} M_{1}\right) \varepsilon_{t}+V_{\cdot 2} M_{2} \boldsymbol{\zeta}_{t}^{*},
$$

where $M_{1}$ is a $(k-r) \times l$ matrix and $M_{2}$ is a $(k-r) \times p$ matrix. When there exists a unique solution or $r=k, V_{\cdot 2}=0$ and and the unique solution is not affected by the sunspot shock $\boldsymbol{\zeta}_{t}^{*}$. When there exist multiple solutions or $r<k, \boldsymbol{\zeta}_{t}^{*}$ affects $\mathbf{z}_{t}$ through their influence on $\boldsymbol{\eta}_{t}$ and also the impact of $\varepsilon_{t}$ on $\boldsymbol{\eta}_{t}$ changes. The new parameters $M_{1}$ and $M_{2}$ are not determined by the structural parameters and Lubik and Schorfheide (2004) propose to treat them as additional parameters. Since $M_{2}$ is not identified in the model, only $(k-r)$ dimensions of the sunspot shocks matter. Lubik and Schorfheide (2004) reparameterize $\boldsymbol{\zeta}_{t}=M_{2} \boldsymbol{\zeta}_{t}^{*}$. Putting the solution of the expectational error $\eta_{t},(7)$, back to the model (3), a solution of the model can be written as

$$
\mathbf{z}_{t}=\Gamma_{1}^{*} \mathbf{z}_{t-1}+\left(\Gamma_{0, \varepsilon}^{*}+\Gamma_{0, \zeta}^{*} M\right) \varepsilon_{t}+\Gamma_{0, \zeta}^{*} \boldsymbol{\zeta}_{t}
$$

\section{C.3 Identification problem}

An identification problem arises because $V_{.2}$, the left singular vectors of a SVD of $Q_{2} . \Pi$ in (6), corresponds to zero singular values and thus is not identified. Because of this problem, $\Gamma_{0, \zeta}^{*}$ in (8) is not well identified. This appears to cause numerical instability in their solution method. For example, small changes in parameter values can easily lead to a large change in the likelihood of a LRE model under indeterminacy.

Since in our model the degree of indeterminacy is at most one, $\Gamma_{0, \zeta}^{*}$ is simply a vector. We identify $\Gamma_{0, \zeta}^{*}$ by normalizing its first entry to its norm. With this normalization, posterior density maximization and simulation of our model is stable and works well. The normalization would affect the posterior distribution of the entries of the matrix $M$ in (8). However, those 
parameters in $M$ do not have behavioral interpretations. What matters is the additional channel for the propagation of the fundamental shocks, $\Gamma_{0, \zeta}^{*} M$, whose posterior distribution is not affected by the normalization if the prior distribution for the entries of $M$ is flat. Although our baseline prior for the entries of $M$ is not completely flat, it is very diffuse and the effect of the normalization is not significant. We tried different specifications for the prior distribution for the entries of $M$, including a uniform prior distribution over $(-5,5)$ and our results were robust to these variations. The same argument applies to $\boldsymbol{\zeta}_{t}$. 